\title{
In vitro development of zebrafish vascular networks
}

Muhammad Ibrahim ${ }^{1,2}$ and Michael K. Richardson ${ }^{1 *}$

1. Institute of Biology Leiden, Leiden University, The Netherlands

2. Institute of Biotechnology and Genetic Engineering, University of Agriculture Peshawar, Pakistan

* Author for correspondence: Institute of Biology Leiden (IBL), Leiden University, Sylvius Laboratory, Sylviusweg 72, 2333 BE, Leiden, The Netherlands. Tel. 0031 (0)71 527

5215, Fax: $0031(0) 715274900$

E. mail: $\underline{\text { m.k.richardson@biology.leidenuniv.nl }}$ 


\begin{abstract}
A major limitation to culturing tissues and organs is the lack of a functional vascular network in vitro. The zebrafish possess many useful properties which makes it a promising model for such studies. Unfortunately, methods of culturing endothelial cells from this species are not well characterised. Here, we tried two methods ( embryoid body culture and organ explants from transgenic zebrafish $k d r l: G F P$ embryos) to develop in vitro vascular networks. In the $k d r l: G F P$ line, endothelial cells expresses green fluorescent protein, which allows to track the vascular development in live cultures. We found that embryoid bodies showed significantly longer and wider branches of connected endothelial cells when grown in a microfluidic system than in static culture. Similarly, sprouting of $k d r l: G F P^{+}$cells from the tissue explants was observed in a 3D hydrogel matrix. This study is a step towards the development of zebrafish vascular networks in vitro.
\end{abstract}

Key words: Angiogenesis; Embryoid bodies; Explant culture; Microfluidics; Vasculogenesis; Zebrafish. 


\section{Introduction}

There are a number of reasons why it could be useful to develop culture systems containing functional vascular networks. For example, tissue engineering is a very important area of biomedical research that may have applications in regenerative medicine and organ transplantation [1]. The in vitro culture of complex tissues might also help our understanding of physiological aspects of organ function [2]; disease conditions such as cardiac disorders [3]; and drug screening [4]. In vivo the vascular system is essential for the growth and development of functional tissues and organs [5]. A major obstacle to engineering an organ in vitro with the current tissue culture procedures is the lack of a vascular network [6]. Development of three-dimensional (3D) culture systems with a functional capillary bed could overcome this problem $[7,8]$.

Development of an in vitro vascular network could also have other applications e.g. vascular regenerative therapy [9] and modelling diseases such as retinal microvascular abnormalities in diabetes [10] and abnormal angiogenesis in tumor development [11]. Vascular culture techniques are important in cancer research for the screening of compounds that inhibit angiogenesis [12]. Furthermore, in vitro vascular networks could also serve as a screening model for candidate drugs, as some of the drugs approved for clinical trials may disturb vascular development. An example of such a drug is thalidomide, whose teratogenicity is linked to anti-angiogenic effects [13].

Protocols for culturing vascular networks have been successfully developed using endothelial cell lines and embryonic tissues [14]. Commonly, human umbilical vein endothelial cells (HUVEC) are used in pure culture or in co-culture with other cells (Table 1). These cultures are established on biological matrices that mimic some of the properties of endogenous extracellular matrix [15]. Blood vessel sprouting has been shown to take place from beads coated with HUVECs, and cultured on a fibrin gel, in media supplemented with vascular endothelial growth factor (VEGF), fibroblast growth factor (FGF), angiopoietin-1 (Ang-1) and transforming growth factor beta (TGF- $\beta$ ) [16]. Endothelial cells from other species have also been adapted for in vitro vasculogenesis; examples include bovine aortic endothelial cells [17] and rat aortic endothelial cells [18] 


\begin{tabular}{|c|c|c|c|c|c|c|c|c|c|c|c|c|}
\hline constituents & & $\begin{array}{c}\text { HUV } \\
\text { EC }\end{array}$ & HEPC & $\begin{array}{c}\text { HEVC } \\
\mathrm{S}\end{array}$ & $\begin{array}{c}\text { ECFC } \\
- \text { EC }\end{array}$ & $\begin{array}{c}\text { HUV } \\
\text { EC }\end{array}$ & $\begin{array}{c}\text { HUV } \\
\text { EC }\end{array}$ & $\begin{array}{c}\text { HUV } \\
\text { EC }\end{array}$ & $\begin{array}{c}\text { HUV } \\
\text { EC }\end{array}$ & BAEC & $\begin{array}{c}\text { HUV } \\
\text { EC }\end{array}$ & $\begin{array}{c}\text { HUVE } \\
\text { C }\end{array}$ \\
\hline Culture system & - & Static & Static & Static & Flow & Flow & Flow & Static & Flow & Static & Static & Static \\
\hline Substrate & - & BME & $\begin{array}{l}\text { Col-I } \\
\text { Fbg } \\
\text { Pmtx }\end{array}$ & $\begin{array}{l}\text { HA- } \\
\text { Hyg }\end{array}$ & Fbg & Fbg & Col-1 & & Col-1 & MG & Fbg & Col-1 \\
\hline Support cells & - & - & $\begin{array}{c}\text { HMP } \\
\text { Cs }\end{array}$ & - & NHLF & $\begin{array}{c}\text { NHLF } \\
\text { HPP }\end{array}$ & - & HDF & $\begin{array}{c}\text { HBVP } \\
\text { HUAS } \\
\text { MC }\end{array}$ & - & - & $\begin{array}{c}\mathrm{HBM} \\
\mathrm{SC}\end{array}$ \\
\hline EGM-2 (Lonza) & - & & & & & & & - & - & - & & \\
\hline DMEM & - & - & - & - & - & - & - & & - & & - & \\
\hline M199 & - & - & & - & - & - & - & - & & - & - & - \\
\hline I-glutamine & - & - & - & - & - & - & - & - & & - & - & - \\
\hline ECGS & - & - & - & - & - & - & - & - & & - & - & - \\
\hline FBS & $\%$ & - & 20 & - & - & - & - & 10 & 16 & 1 & - & 1 \\
\hline bFGF & $\mathrm{ng} / \mathrm{ml}$ & - & - & - & - & - & - & - & 50 & - & 25 & - \\
\hline VEGF & $\mathrm{ng} / \mathrm{ml}$ & - & - & - & - & - & - & - & 50 & 50 & 25 & - \\
\hline L-ascorbic acid & $\mathrm{ng} / \mathrm{ml}$ & - & - & - & - & - & - & - & 50 & - & - & - \\
\hline $\mathrm{O}_{2}$ & $\%$ & - & - & - & 5 & - & - & - & - & - & - & - \\
\hline CS-extract & ratio & - & - & - & - & - & - & $1 / 128$ & - & - & - & - \\
\hline $\mathrm{P} / \mathrm{S}$ & $\%$ & - & - & - & - & - & - & - & 1 & - & - & 1 \\
\hline PMA & $\mathrm{ng} / \mathrm{ml}$ & - & - & - & - & - & - & - & 50 & - & - & - \\
\hline rGal-8 & $\mathrm{nM}$ & - & - & - & - & - & - & - & - & $5-20$ & - & - \\
\hline References & & [19] & {$[20]$} & {$[21]$} & {$[22]$} & [23] & [24] & {$[25]$} & {$[26]$} & [17] & [16] & [27] \\
\hline
\end{tabular}

Abbreviations: HUVEC, human umbilical vein endothelial cells; HEPC, Human endothelial progenitor cells; HEVCs, human early vascular cells; ECFC-EC, human endothelial colony forming cell-derived endothelial cells; BAEC, bovine aortic endothelial cells; Static, static replacement culture; Flow, microfluidic flow-through culture; BME, basement membrane extract (Trevigen); Pmtx, puramatrix; Fbg, fibrinogen; Col-I, collagen type-I; HA-Hyg, hyaluronic acid based hydrogel; MG, matrigel; HMPCs, human mesenchymal progenitor cells; NHLF, human normal lungs fibroblasts; HPP, human placental pericytes; HDF, human dermal fibroblasts; HBVP, human brain vascular pericytes; HUASMC, human umbilical cord arterial smooth muscle cells; HBMSC, human bone marrow-derived mesenchymal stem cells; EGM, endothelial growth medium; DMEM, Dulbecco's modified Eagle's medium; M199, medium 199 from Lonza; ECGS, endothelial cell growth supplement; FBS, fetal bovine serum; bFGF, basic fibroblast growth factor; VEGF, vascular endothelial growth factor; CS-extract, calcium silicate extract from bioceramics; P/S, penicillin/streptomycin; PMA, phorbol-12-myristate-13-acetate; rGal-8, recombinant galectin-8; grey boxes indicate the base medium; -, not added.

Another method for culturing vascular networks is the embryoid body culture. Embryoid bodies (EBs) are three-dimensional (3D) aggregates of embryonic stem cells isolated from blastocyst stage embryos [28]. In an embryoid body culture the endothelial cells differentiate and form blood vessels in a complex environment, which reflects vascular formation in early embryos [29]. Unlike pure endothelial cell cultures, multiple cell types are involved in vessel formation in EB culture [30]. Vasculogenesis starts at day 3 of hanging drop cultures in mouse EBs [31]. These EBs show sprouting of blood vessel-like structures, into the surrounding matrix, when transferred to two-dimensional (2D) or 3D collagen gel [31].

As an alternative, embryonic tissue explants are also used as precursors for culturing blood vessels (Table 2). Similar to the EBs, tissue explants contain multiple cell types required for 
the formation of blood vessels [14]. Furthermore, the cells in the explants are thought to be closer to the in vivo state, compared to repeatedly passaged endothelial cell lines [14]. A disadvantage of using tissue explants for the culture of vascular networks is that the growth rate of the cells in the explant is slower than in the cell lines [32]. One of the commonly-used tissue explants capable of developing blood vessel sprouts in vitro is the cross section of rat or mouse aorta called the aortic ring [33]. Other potential explants include fragments of embryonic mouse metatarsal bones [34], mouse retina [35] and rat kidney [36] tissues.

Table 2: Culture conditions used to form in vitro vascular networks using tissues explants.

\begin{tabular}{|c|c|c|c|c|c|c|c|c|}
\hline \multirow[t]{2}{*}{ Constituents } & \multirow[t]{2}{*}{ Units } & \multicolumn{7}{|c|}{ Embryonic tissue explant } \\
\hline & & $\begin{array}{l}\text { Mouse } \\
\text { retina }\end{array}$ & $\begin{array}{l}\text { Mouse } \\
\text { AT }\end{array}$ & $\begin{array}{l}\text { Mouse } \\
\text { MT }\end{array}$ & $\begin{array}{l}\text { Mouse } \\
\text { MT }\end{array}$ & $\begin{array}{l}\text { Mouse } \\
\text { MT }\end{array}$ & $\begin{array}{l}\text { Mouse } \\
\text { AR }\end{array}$ & $\begin{array}{l}\text { Mouse } \\
\text { LV }\end{array}$ \\
\hline Culture system & & Static & Static & Static & Static & Static & Static & Static \\
\hline Substrate & & Fibrin & $\underset{\mathrm{TM}}{\text { Matrigel }}$ & $\begin{array}{c}\text { Collage } \\
n(I)\end{array}$ & $\begin{array}{c}\text { Collage } \\
n(I)\end{array}$ & - & $\begin{array}{c}\text { Collage } \\
n(I)\end{array}$ & Fibrin \\
\hline DMEM & & & - & - & - & - & - & \\
\hline EBM-2 & & - & & - & - & - & - & - \\
\hline$\alpha-M E M$ & & - & - & & & & - & - \\
\hline MCDB131 & & - & - & - & - & - & & - \\
\hline FBS & $\%$ & 10 & 5 & 10 & 10 & 10 & - & 10 \\
\hline VEGF & $\mathrm{ng} / \mathrm{ml}$ & 100 & 0.5 & 50 & - & - & - & 5 \\
\hline hEGF & $\mathrm{ng} / \mathrm{ml}$ & - & 5 & - & - & - & - & - \\
\hline bFGF & $\mathrm{ng} / \mathrm{ml}$ & - & 10 & - & - & - & - & 10 \\
\hline PDGF-BB & $\mathrm{ng} / \mathrm{ml}$ & - & - & - & - & - & - & 10 \\
\hline R3-IGF & $\mathrm{ng} / \mathrm{ml}$ & - & 20 & - & - & - & - & - \\
\hline $\mathrm{P} / \mathrm{S}$ & $\%$ & - & - & 1 & 1 & 1 & - & - \\
\hline GA & $\%$ & 1 & - & - & - & - & - & - \\
\hline Penicillin & $\mathrm{U} / \mathrm{ml}$ & - & - & - & - & - & 100 & - \\
\hline Streptomycin & $\mu \mathrm{g} / \mathrm{ml}$ & - & - & - & - & - & 100 & - \\
\hline Rapamycin & $\mathrm{nM}$ & - & - & - & - & - & - & 10 \\
\hline Ascorbic acid & $\mu \mathrm{g} / \mathrm{ml}$ & - & 1 & - & - & - & - & - \\
\hline Hydrocortisone & $\mu \mathrm{g} / \mathrm{ml}$ & - & 0.2 & - & - & - & - & - \\
\hline $\mathrm{NaHCO}_{3}$ & $\mathrm{mM}$ & - & - & - & - & - & 25 & - \\
\hline Mouse serum & $\%$ & - & - & - & - & - & 2.5 & - \\
\hline Glutamine & $\%$ & - & - & - & - & - & 1 & - \\
\hline References & & {$[35]$} & [37] & [38] & [39] & [34] & {$[40]$} & [41] \\
\hline
\end{tabular}

Abbreviations: AT, adipose tissue; MT, metatarsal; AR, aortic ring; LV, left ventricle; DMEM, Dulbecco's modified Eagle's medium; EBM-2, endothelial basal medium from Lonza; $\alpha$-MEM, minimal essential medium from Gibco; MCDB131, basal medium life technologies; FBS, fetal bovine serum; VEGF, vascular endothelial growth factor; hEGF, human epidermal growth factors; bFGF, basic fibroblast growth factor; PDFG-BB, platelets derived growth factor; R3-IGF, insulin like growth factors; $P / S$, penicillin/streptomycin; $G A$, gentamycin/amphotericin-B; grey boxes indicate the basal medium; -, not added.

Haemodynamic, or the mechanical forces produced by blood flow, influence the expression of several biochemical pathways in the endothelial cells; these in turn can modulate the structure and function of blood vessels [42]. In addition to the different techniques 
discussed above for culturing vascular networks, the role of haemodynamic factors has been studied using microfluidic or lab-on-a-chip technology [43]. By combining 3D culture in a hydrogel (which mimics the natural ECM) with microfluidics (which mimics the blood flow), an in vitro environment can be created which could be in principle, close to the in vivo environment for vascular morphogenesis $[8,44]$. Advances in microfluidics and 3D culture technologies have greatly increased the possibilities for developing functional vascular models and vascularized tissues [44]. However, the challenges in selecting an appropriate microfluidic system and 3D matrix for culturing blood vessels, that can vascularize complex tissues in vitro, still need to be resolved [44].

Most of the current procedures for culturing blood vessels discussed above, involve cells or tissues from mouse, humans or other species. These techniques are associated with certain limitations. Human endothelial cell lines are not thought to closely represent the in vivo state of the endothelial cells [14]. Furthermore, these cell lines change their gene expression and physiological properties with repeated passaging in vitro, and may lose their ability to form vascular networks [14]. Mouse embryonic tissues are difficult to isolate because of the internal fertilisation and in utero development of the embryo. Techniques for the isolation of embryonic stem cells and organ explants from mammals are more costly, require invasive surgical procedures and can raise ethical concerns $[9,45]$. Furthermore, mouse aortic explant cultures have shown significant variability between the experiments [46].

For these reasons, it is desirable to explore the possibilities offered by alternative models. The zebrafish is one such emerging model species[47]. In contrast to the mouse, the external fertilization in zebrafish allows easy access to a large number of embryos, as well as cells or tissues isolated from these embryos, for in vitro studies [48, 49]. Zebrafish early embryonic cells or adult stem cells have been used for ex vivo experiments; fewer have used cells from larvae $[49,50]$. Zebrafish whole embryos and isolated cells are currently being developed as potential alternative screening models for toxicity analysis [51, 52].

Many of the organ primordia of zebrafish are formed during the first $72 \mathrm{~h}$ of embryo development [53]. There are practical advantages of zebrafish for cell culture e.g. they can be maintained in a simple incubator without additional $\mathrm{CO}_{2}$ supply [54]. Zebrafish embryos are optically transparent until early larval stages [55]. Furthermore, the genetically-modified 
zebrafish line kdrl:GFP expresses green fluorescent protein (GFP) on the surface of its endothelial cells [56]. In this line, the development of blood vessels can be tracked using confocal microscopy [57]. Zebrafish kdrl:GFP embryos and embryonic cell culture have been used for analysing the toxic effect of different compounds on vascular development $[58,59]$.

Our ultimate goal is to develop an in vitro model of vascular networks using zebrafish embryonic cells, as an alternative to currently used mouse and human cell culture models. To achieve this aim, we describe here procedures for culturing zebrafish EBs and embryonic organ explants for sprouting angiogenesis. We first compare the growth of vascular networklike structures in kdrl:GFP EB cultures, maintained with or without microfluidic flow. We shall refer to the cultures without microfluidic flow as 'static' cultures. The EB cultures were derived from blastocyst stage zebrafish embryos at $3.5 \mathrm{~h}$ post fertilization (hpf). Second, we describe the culture of zebrafish organ explants (liver and heart) isolated from aseptically grown 5 days post fertilization (dpf) embryos for sprouting angiogenesis. These explant cultures were developed in order to further optimize the culture conditions for these tissues, as cells derived from different tissues and at different developmental stage of embryo may have different culture requirements. Using the knowledge gained from these studies in zebrafish, we hope one day to extend the techniques to cells from other species.

\section{Materials and methods}

\subsection{Zebrafish embryos}

All the animal experiments were performed according to the Netherland experiments on Animals act [60], based on EU directives [61]. Adult kdrl:GFP zebrafish were maintained in circulating water according to previously described protocols [62]. Adult male and female fish, at a proportion of 1:1, were transferred to breeding tanks in the evening. The eggs were collected, next morning, at the bottom of the tank, separated from adults using a mesh to prevent the eggs from being eaten. Fertilized, healthy embryos were distributed in $9 \mathrm{~cm}$ Petri dishes (100 embryos per dish for EB culture and 50 embryos per dish for liver and heart isolation). The embryos used for EB culture were allowed to grow for $3.5 \mathrm{~h}$, and the embryos for liver and heart isolation for $24 \mathrm{~h}$ in a temperature controlled room at $28^{\circ} \mathrm{C}$. 
When zebrafish eggs are laid, they are exposed to a wide range of pathogens in the water including faecal pathogens from the adults [63]. The chorion represents a barrier to the entry of microorganisms into the perivitelline space and embryo [64]. Therefore, before isolating cells and tissues we decontaminated the eggs with their intact chorion.

\subsection{Embryo sterilization}

The embryos were surface decontaminated, with the chorion intact, using a procedure modified from Ref. [65]. Briefly, the embryos were transferred to a small net and immersed in $70 \%$ ethanol for $10 \mathrm{sec}$. The embryos were then washed with L15 medium (Table 3) to remove the ethanol. The embryos were then immersed twice, for 4 min each, in sodium hypochlorite solution (Table 3), with a change of L15 medium in between. After the last treatment with sodium hypochlorite the embryos were washed three times with L15 medium and finally left in $500 \mu \mathrm{L}$ of $\mathrm{L} 15$ medium for dechorionation.

\subsection{Embryo dechorionation}

The embryos decontaminated in the previous step, still with their chorions intact, were subjected to manual dechorionation under a dissecting microscope using a pair of sterile No.5 watchmaker's forceps. The dead embryos, or embryos with cloudy perivitelline fluid were removed before dechorionation.

\subsection{Embryoid body culture}

The $3.5 \mathrm{hpf}$ blastocyst stage embryos, after sterilization and dechorionation were transferred to Eppendorf tubes (100 blastocysts per tube) using a P-1000 Gilson pipette. The blastocysts were triturated using a P-200 Gilson pipette and then centrifuged at 300g for 1 min to remove most of the yolk. The supernatant was removed and the blastocysts were treated for two minutes with $1 \mathrm{~mL}$ trypsin solution (Table 3 ) with gentle trituration using a P1000 pipette. The trypsinization was stopped by adding $100 \mu \mathrm{L}$ of fetal bovine serum (FBS; Invitrogen, Cat. No. 10500), and the cells were pelleted by centrifuging the mixture at $300 \mathrm{~g}$ for $3 \mathrm{~min}$. The cells were washed three times with $500 \mu \mathrm{L}$ of LDF medium (Table 3 ) and then re-suspended in $200 \mu \mathrm{L}$ of the same medium. The cell concentration was determined using heamocytometer and the suspension was cultured in hanging drops to initiate the formation of EBs. 


\subsubsection{Hanging drop culture}

The blastocyst cell suspension was diluted to a final concentration of 50 cells/ $\mu \mathrm{L}$ in LDF medium supplemented with $10 \%$ FBS, $4.1 \%$ endothelial growth supplement mix (EGS; Promocell; bio-connect B.V.; Cat. No. C-39216), 50 ng/mL recombinant zebrafish vascular endothelial growth factor (VEGF $165 ;$ R\&D systems, Cat. No. $1247-Z V$ ) and $10 \mathrm{ng} / \mathrm{mL}$ recombinant human basic fibroblast growth factor (bFGF; Invitrogen, Cat. No. PHG0024). This solution was distributed in $20 \mu \mathrm{L}$ droplets (1000 cells per drop) onto the inside of the lid of $60 \mathrm{~mm}$ Petri dishes. Calcium- and magnesium-free phosphate buffered saline (CMF-PBS) was added to the Petri dishes to humidify the air and thereby reduce evaporation from the droplets. The lids with the droplets were carefully inverted on the Petri dishes and the cultures were left for four days in a humidified incubator at $28{ }^{\circ} \mathrm{C}$ and $0.5 \% \mathrm{CO}_{2}$, to allow the cells to aggregate and form EBs.

\subsubsection{EB culture in $3 D$ gel matrix}

On day 4 of hanging drop culture, the EBs were collected from the hanging drops by inverting the lid and gently tapping it while holding it at $45^{\circ}$ angle. The droplets with the EBs collected on one side of the lid and were then transferred to a $1.5 \mathrm{~mL}$ Eppendorf tube (100 EBs per tube) using a P-1000 pipette. The EBs were allowed to settle down to the bottom of the tube by gravity and were washed once with $500 \mu \mathrm{L}$ of LDF medium. Finally, the EBs were re-suspended in $100 \mu \mathrm{L}$ of LDF medium.

The EBs were then transferred to a 3D gel matrix composed of collagen type-I, Geltrex ${ }^{\mathrm{TM}}$ and fibrin $(2.5+6-9+2 \mathrm{mg} / \mathrm{mL})$. The 3D EB cultures were maintained under static replacement conditions in CS16-chambered coverglass plate (Grace Bio; Cat. No. 112358), or under microfluidic conditions in a microchannel slide (Ibidi, sticky-slide $\mathrm{VI}^{0.4}$; Cat. No. 80608; Figure $1 \mathrm{~A})$. The gel was prepared by mixing the calculated volumes of collagen type-I $(5 \mathrm{mg} / \mathrm{mL}$; Ibidi, Cat. No. 50201), Geltrex ${ }^{\mathrm{TM}}$ (12-18 mg/mL; Invitrogen, Cat. No. A1413201) and bovine fibrinogen (10 mg/mL; Sigma, Cat. No. F8630) on ice. The solution was diluted, to achieve the desired concentrations, using 10X CMF-PBS and LDF medium and was supplemented with VEGF $165(50 \mathrm{ng} / \mathrm{mL}$ ). Thrombin (final concentration 3 Units/mL; Sigma, Cat. No. T4648) was added to the gel mixture to polymerize the fibrinogen. 
To initiate the cultures, the wells of the chambered coverglass plate or the bottom cover glass slide of the microchannel sticky-slide (Figure 1B and C) was coated with a thin layer of the gel mixture. The plate and slide with the gel coating were incubated at $28^{\circ} \mathrm{C}$ for $30 \mathrm{~min}$. The EBs were then plated in the coated well and on the coated area of the slide (20 EBs per well or per coated area on slide). The plates and slides with the EBs were again incubated for $30 \mathrm{~min}$ at $28^{\circ} \mathrm{C}$, and the excess medium was then removed and another layer of the gel was applied on the top of the EBs (Figure 1D).

After a third incubation at $28^{\circ} \mathrm{C}$ for $30 \mathrm{~min}, 250 \mu \mathrm{L}$ of the LDf medium supplemented with $5 \% \mathrm{FBS}, 4.1 \% \mathrm{EGS}, 50 \mathrm{ng} / \mathrm{mL}$ VEGF165 and $10 \mathrm{ng} / \mathrm{mL}$ bFGF was added to the wells prepared for static cultures. The microchannel slide was sealed (Figure 1E) and connected to a medium reservoir with the same medium and a syringe pump (Pump 11 Pico Plus Elite; Harvard Apparatus; item No. 70-4506; Figure 1F). The medium was drawn through the culture chamber at a flow rate of $20 \mu \mathrm{L} / \mathrm{min}$. The medium reservoirs were filled with $10 \mathrm{~mL}$ of the medium, which was enough for approximately eight hours of perfusion. Every eight hours, the reservoirs were refilled with the withdrawn medium. This was repeated until the end of the experiment. The cultures were maintained in the incubator at $28{ }^{\circ} \mathrm{C}$ and $0.5 \% \mathrm{CO}_{2}$. For static conditions the medium was refreshed at day 4 of culture.
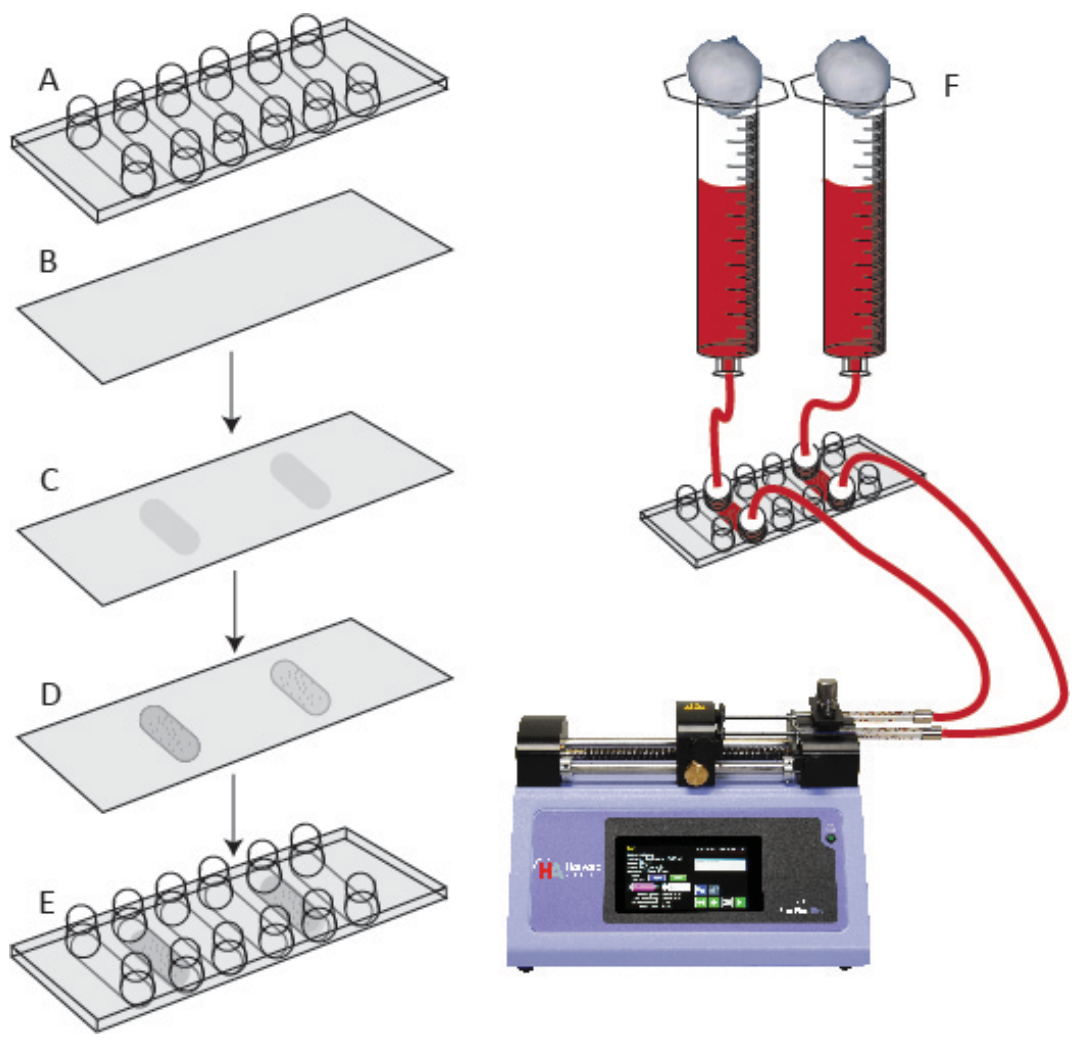
Figure 1: Microfluidic flow-through culture setup. (A) Ibidi six-microchannel sticky-slide. (B) Cover glass slide. (C) Applied gel mixture coating on the cover glass slide at the point where the slide will come in contact with the channels. (D) Embryoid bodies and another layer of gel mixture added to the coated area. (E) The cover glass with embryoid bodies embedded in gel is glued to the bottom of the slide. (F) The channels with embryoid bodies in 3D gel are connected to media reservoirs and Harvard syringe pump to start the media flow through the channels.

\subsection{Aseptic culture of embryos for liver and heart isolation}

The embryos ( $24 \mathrm{hpf}$ ) decontaminated and dechorionated according to the procedure described above (Section 2.2. Embryo sterilization and 2.3. Embryo dechorionation) were raised for 5 days in Petri dishes in $25 \mathrm{~mL}$ of the embryo medium (Table 3). The Petri dishes were sealed using $3 \mathrm{M}^{\mathrm{TM}}$ Micropore ${ }^{\mathrm{TM}}$ surgical tape to allow gas exchange while ensuring asepsis. These embryos were raised in a temperature-controlled room at $28^{\circ} \mathrm{C}$ in $14 \mathrm{~h}$ light: $10 \mathrm{~h}$ dark cycle.

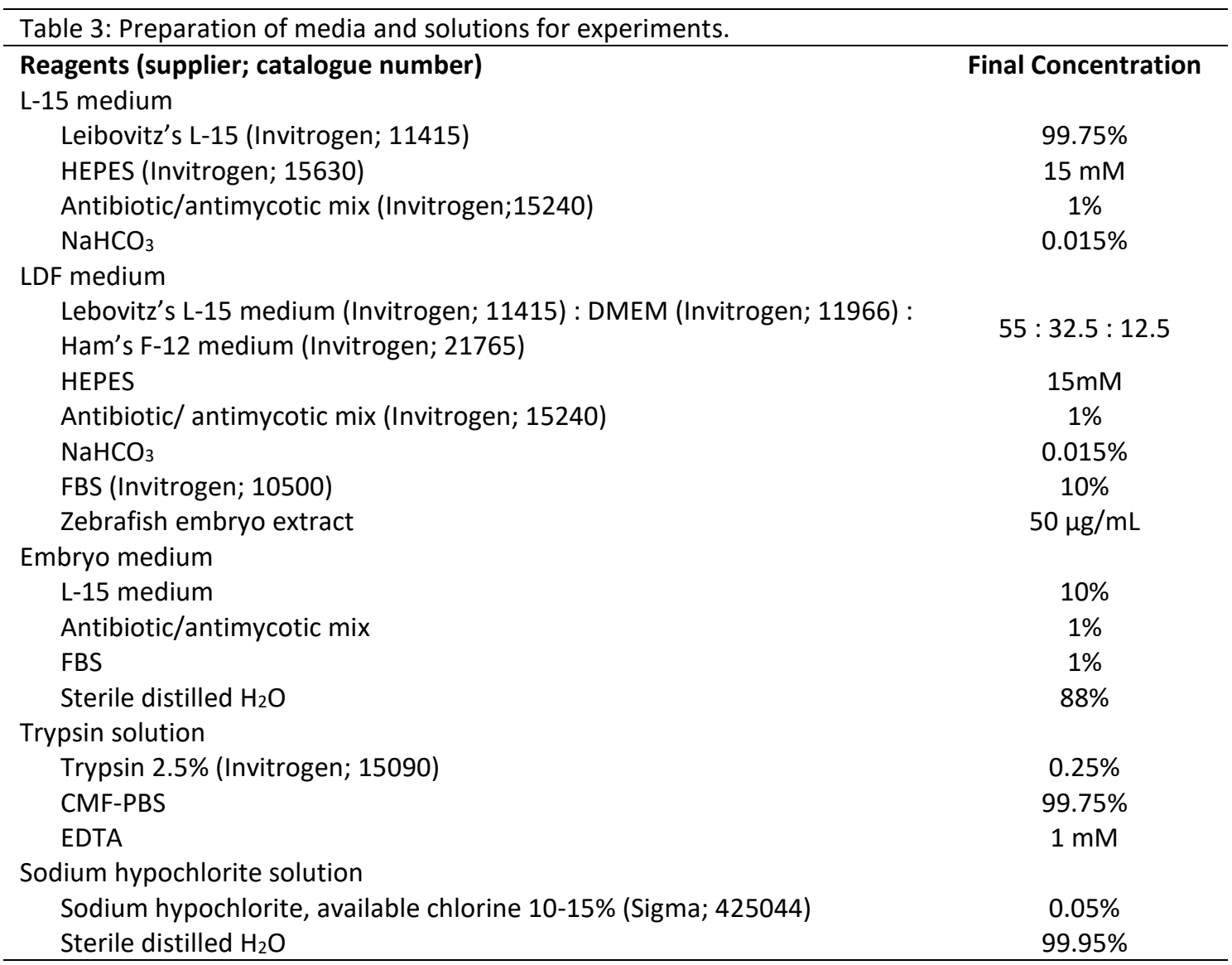

Abbreviations : HEPES, 4-(2-hydroxyethyl)-1-piperazine-ethanesulfonic acid; DMEM, Dulbecco's modified Eagle's medium; FBS, fetal bovine serum; CMF-PBS, calcium magnesium free phosphate buffer saline; EDTA, ethylenediaminetetraacetic acid. 


\subsection{Isolation of embryonic liver and heart tissues}

To isolate liver and heart tissues, each of the $5 \mathrm{dpf}$ embryos was transferred to a $16 \mu \mathrm{L}$ drop of L-15 medium containing $10 \% \mathrm{FBS}$ and $0.16 \mathrm{mg} / \mathrm{mL}$ tricaine methane sulfonate (TMS) solution to anaesthetise them. The tissues were isolated by dissecting the embryo using a pair of sterile No.5 watchmaker's forceps. After they were dissected out, the liver and heart tissues were transferred to Eppendorf tubes (with the liver and heart tissue in separate tubes) in $100 \mu \mathrm{L}$ of L-15 medium containing 10\% FBS at room temperature. The tissues from 100 embryos were pooled in one Eppendorf tube.

\subsection{Explant cultures}

The liver or heart explants were embedded in 3D hydrogels for culturing. Different substrate compositions were used to prepare the gel matrices. Liver explants were cultured in two different gel matrices: (i) Collagen type-I + Geltrex ${ }^{\mathrm{TM}}+$ fibrin $(2.5+6-9+2 \mathrm{mg} / \mathrm{mL})$, (ii) Geltrex $^{\mathrm{TM}}(12-18 \mathrm{mg} / \mathrm{mL})$. The heart explants were cultured in Collagen type-I + Geltrex ${ }^{\mathrm{TM}}+$ fibrin $(2.5+6-9+2 \mathrm{mg} / \mathrm{mL})$ matrix. The 3D cultures were prepared according to the procedure described in section 2.4.2. EB culture in 3D gel matrix.

\subsection{Culture of dissociated liver and heart cells}

The liver and heart tissues isolated from 100 larvae were dissociated to make single-cell suspensions. The liver tissues were dissociated using trypsin. Briefly, the isolated livers were washed once with $500 \mu \mathrm{L}$ CMF-PBS and then incubated for two min at room temperature with $1 \mathrm{~mL}$ of trypsin solution (Table 3) with gentle trituration using a P-1000 Gilson pipette. FBS $(100 \mu \mathrm{L})$ was added to inactivate the trypsin. The heart tissues were dissociated into a single cell suspension using Liberase TL (Sigma, Cat. No. 05401020001) solution. Briefly the hearts were incubated for 30 minutes at $28^{\circ} \mathrm{C}$, in $1 \mathrm{~mL}$ Liberase $\mathrm{TL}$ solution $(0.4 \mathrm{mg} / \mathrm{mL})$ with occasional trituration using a P-1000 pipette. The solutions were centrifuged at $300 \mathrm{~g}$ for 3 min to form a cell pellet, and the supernatant discarded. The cell pellet was washed three times with L-15 medium containing $10 \%$ FBS and then re-suspended in $100 \mu \mathrm{L}$ of the same medium.

The cell suspension was mixed at a 1:1 ratio with trypan blue dye (0.4\% trypan blue in CMFPBS), and loaded on a heamocytometer. The number of $k d r l: G F P^{+}$and $k d r l: G F P^{-}$cells inside the grid of the heamocytometer was counted under a confocal microscope. From these 
counts the number of $k d r l: G F P^{+}$cells and total number of cells per microliter was calculated. The percentage of $k d r l: G F P^{+}$cells and the total number of cells in the isolates from 100 tissues was calculated from these numbers. Finally, the cell suspension was distributed at 20,000 cells per well in the pre-coated wells of the CS16-chambered coverglass plate.

The trypsinized liver cells were cultured on four different 2D substrates: (i) collagen type-I + Geltrex ${ }^{\mathrm{TM}}+$ fibrin $(2.5+6-9+2 \mathrm{mg} / \mathrm{mL})$, (ii) collagen type-I + Geltrex ${ }^{\mathrm{TM}}(2.5+6-9 \mathrm{mg} / \mathrm{mL})$, (iii) Geltrex $^{\mathrm{TM}}(12-18 \mathrm{mg} / \mathrm{mL})$, (iv) tissue culture treated glass surface with no additional substrate added. The wells of the chambered coverglass plate were coated with $5 \mu \mathrm{L}$ of the desired gel mixture per well and the plate was incubated at $28^{\circ} \mathrm{C}$ for $30 \mathrm{~min}$. The dissociated heart cells were cultured on Fibronectin (Gibco; Cat. No. 33010018) substratum $\left(1 \mu \mathrm{g} / \mathrm{cm}^{2}\right)$. The fibronectin stock solution $(1 \mu \mathrm{g} / \mu \mathrm{L})$ was diluted using CMF-PBS and $5 \mu \mathrm{L}$ of the diluted solution (containing $0.3 \mu \mathrm{g}$ fibronectin) was added per well. The plate was incubated at $28^{\circ} \mathrm{C}$ for $30 \mathrm{~min}$ and then air dried at room temperature. Before addition of cells, the wells coated with any of the above substrate were washed once with $200 \mu \mathrm{L}$ of $\mathrm{L} 15$ medium.

The dissociated cells or explants cultures derived from liver and heart tissues were cultured in L-15 medium supplemented with $15 \% \mathrm{FBS}, 50 \mu \mathrm{g} / \mathrm{mL}$ zebrafish embryo extract (ZEE), 4.1\% EGS, $50 \mathrm{ng} / \mathrm{ml} \mathrm{VEGF}_{165}$ and $10 \mathrm{ng} / \mathrm{ml} \mathrm{bFGF}$. The cultures were maintained in incubator at 28 ${ }^{\circ} \mathrm{C}$ in atmospheric air. The medium was refreshed every second day.

\subsection{Imaging of cultures}

All the cultures were established in CS16-chambered coverglass plates (Grace Bio; Cat. No. 112358) or on coverglass slides for confocal imaging. The cultures were imaged every second day. The EB cultures were maintained until 12 days, while the liver and heart explant and dissociated cell cultures were maintained until six days. Excitation light of $488 \mathrm{~nm}$ wavelength was used to visualize the $k d r l: G F P^{+}$(putative endothelial) cells in cultures. Live cultures at subsequent time-points were imaged to observe the development of vascular network-like structures from $k d r l: G F P^{+}$cells in the EB and dissociated liver and heart cell cultures. Similarly, the explant cultures were imaged to observe changes in the existing vascular networks, and sprouting of the $k d r l: G F P^{+}$cells from explants into the surrounding matrix overtime. 


\subsection{Data collection and analysis}

The EB cultures were assessed for percentage change in the total $k d r l: G F P^{+}$area per EB, total length and number of the $k d r l: G F P^{+}$strands per EB, and average length and width of the $k d r l: G F P^{+}$strands. The connectedness of the $k d r l: G F P^{+}$cell network per EB was calculated by dividing the number of endpoints by the number of junctions of the network.

The images of the explant cultures were measured for total $k d r l: G F P^{+}$area per explant on subsequent time-points of cultures. In addition, the number and average length of $k d r l: G F P^{+}$ branches was also calculated per explant. All the measurements were made in Image-J software version 1.46r [66].

The data were analysed for mean and standard error using SPSS software version 21.0. Variations in measurements at different time-points of culture and between different substrate conditions were assessed by calculating the $p$-value using a one-way ANOVA test with SPSS software.

\section{Results}

\subsection{Development of $k d r l: G F P^{+}$cell networks in EB culture}

The EBs isolated from hanging drop cultures showed a radial network of $k d r l: G F P^{+}$cells inside the EBs (Figure 2, day 2). When these EBs were cultured in 3D gel matrix, the sprouting of $k d r l: G F P^{+}$cells was observed in the surrounding matrix, so as to form a networklike structure (Figure 2). The sprouting appeared to be random; however, in some cases we did observe sprouting in the direction of a nearby EB. Network formation by kdrl:GFP ${ }^{+}$cells was observed only when a mixture of collagen type-I, Geltrex ${ }^{\mathrm{TM}}$ and fibrin gel was used as the matrix. The 3D gel matrices composed of a single gel type, or the combination of two (i.e. collagen type-I and Geltrex ${ }^{\mathrm{TM}}$ ) did not show any development of networks.

The minimum flow rate required for the formation of $k d r l: G F P^{+}$cell networks in our microfluidic system was $20 \mu \mathrm{L} / \mathrm{min}$. At lower flow rates (i.e. 2 and $10 \mu \mathrm{L} / \mathrm{min}$ ) the $k d r l: G F P^{+}$ cells failed to form network-like structures in the microfluidic channel (data not shown). Under these lower flow rates the $k d r l: G F P^{+}$cells were mostly rounded in shape and did not attain the elongated shape as they do when forming a network. The 3D gel combination 
(collagen type-l, $2.5 \mathrm{mg} / \mathrm{mL}+$ Geltrex $^{\mathrm{TM}} 6-9 \mathrm{mg} / \mathrm{mL}+$ fibrin $2 \mathrm{mg} / \mathrm{mL}$ ) was found to be physically stable in the microfluidic culture at $20 \mu \mathrm{L} / \mathrm{min}$ flow rate. This gel combination was also used for 3D static culture of EBs for comparison (Figure 2). Microfluidic cultures with lower concentrations of the gel components could not be maintained because of tearing of the gel caused by medium flow (data not shown).

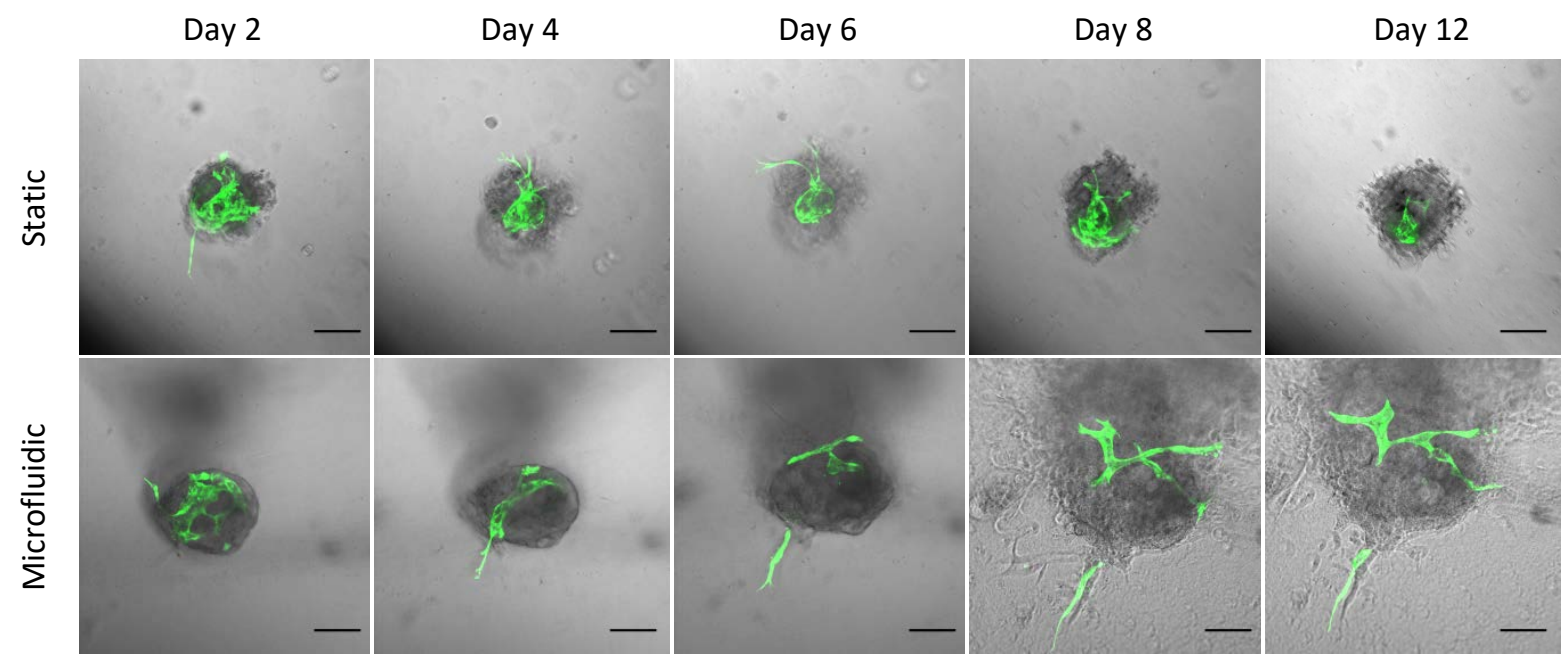

Figure 2 Time-lapse imaging of kdrl:GFP EB cultures in 3D Collagen type-I + Geltrex ${ }^{\mathrm{TM}}+$ Fibrin matrix. Each horizontal row shows the same field. A round network can be observed inside the EBs on day 2 of culture. A reduction in the $k d r l: G F P^{+}$cells network (green) can be observed in static culture after day 6 . In microfluidic culture the network can be observed until day 12. (See also Figure 3 and Figure 4). Scale bar, $100 \mu \mathrm{m}$

\subsubsection{Changes in length and area of the kdrl:GFP+ cell network in EB culture}

Percent changes with time in the dimensions of $k d r l: G F P^{+}$cell networks in 3D static and microfluidic culture are presented in Figure 3 . The results show a gradual decrease in the length and area of the network under static culture conditions; both the length and area became significantly reduced between days 2 and 12 ( $p<0.001)$. In microfluidic culture the same measurements did not decline significantly with time. The change in length of $k d r l: G F P^{+}$cell networks per EB was similar between static and microfluidic cultures at different time points (Figure 3A). However, the decrease in the total area of the network per EB in static culture over time resulted in significant differences between static and microfluidic cultures after day 8 (Figure 3B). 

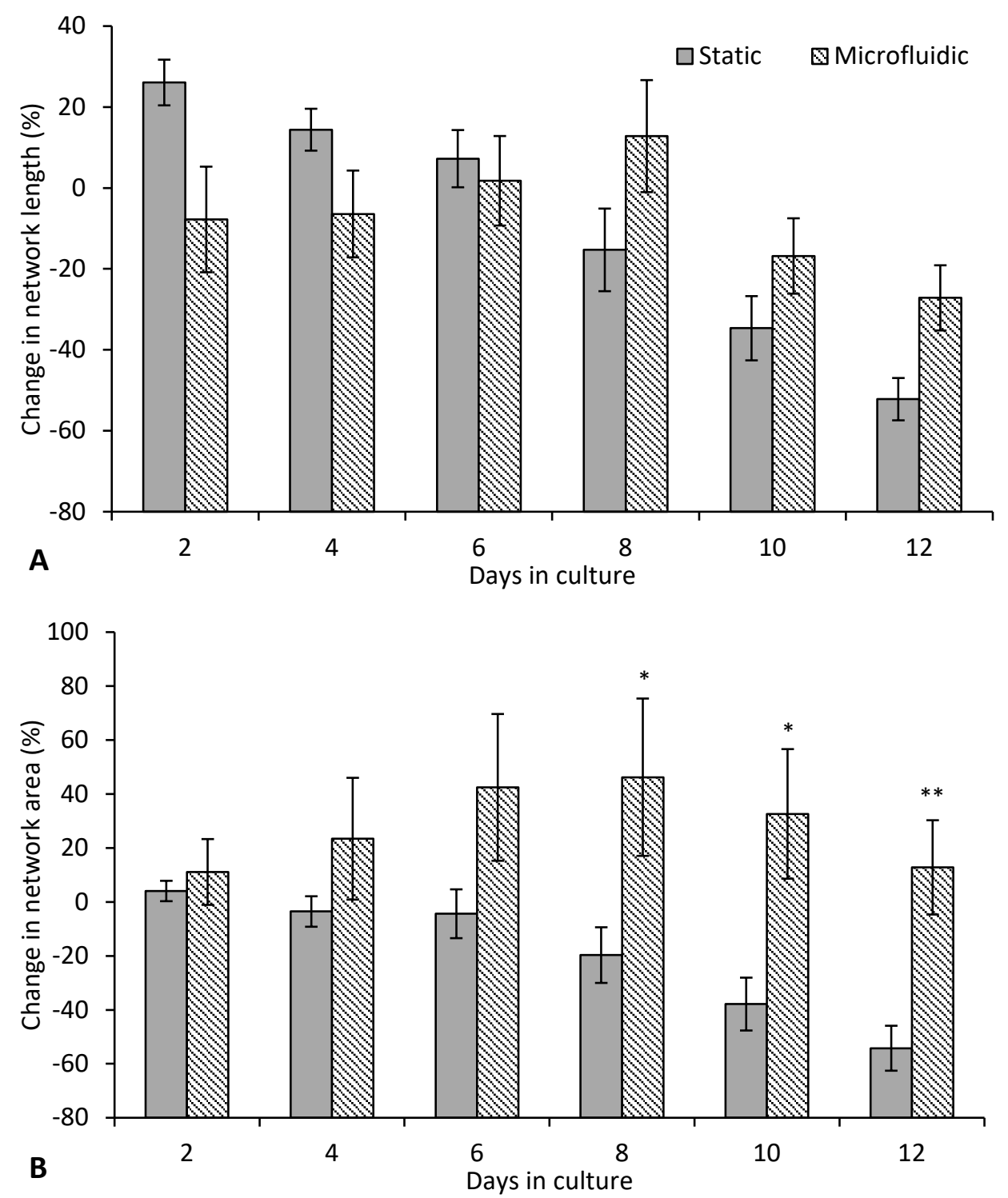

Figure 3. Percent changes, compared to day 1, in length (A) and area (B) of $k d r l: G F P^{+}$cell network in 3D Collagen type-I + Geltrex ${ }^{\mathrm{TM}}+$ Fibrin matrix. In conventional (static) 3D cultures a decline in the kdrl:GFP expression can be observed, while in microfluidic culture the expression is more stable. (A) Percent change in total length of $k d r l: G F P^{+}$cell network per EB. (B) Percent change in total area covered by $k d r l: G F P^{+}$cells per EB. Number of observations were 12 for Static and eight for Microfluidic cultures. Error bars represent standard error. $(* *, p<.01, *, p<.05)$.

\subsubsection{Morphometry of kdrl:GFP ${ }^{+}$networks in EB culture}

The number of branches per EB was higher in static culture (Figure 4A). However, the EBs developed significantly longer and wider branches of connected $k d r l: G F P^{+}$cells in microfluidic than in static culture (Figure $4 \mathrm{~B}$ and C). A higher number of shorter branches in the static culture, and a lower number of longer branches in the microfluidic culture, resulted in a similar total network length in both culture conditions (Figure 4D). However, on 
days 2 and 4 the total network length per EB was higher in static culture compared to microfluidic culture.

Under static culture conditions, the number of branches per EB, and the average branch length and width, was similar at different time points. The total network length per EB in static culture became significantly reduced from day 4 to day $12(p<0.001)$. Under microfluidic conditions an increase was observed in branch length $(p<0.001)$ and width $(p<0.01)$ between days 1 and 8 . The number of branches and total network length per EB remained similar in microfluidic culture.
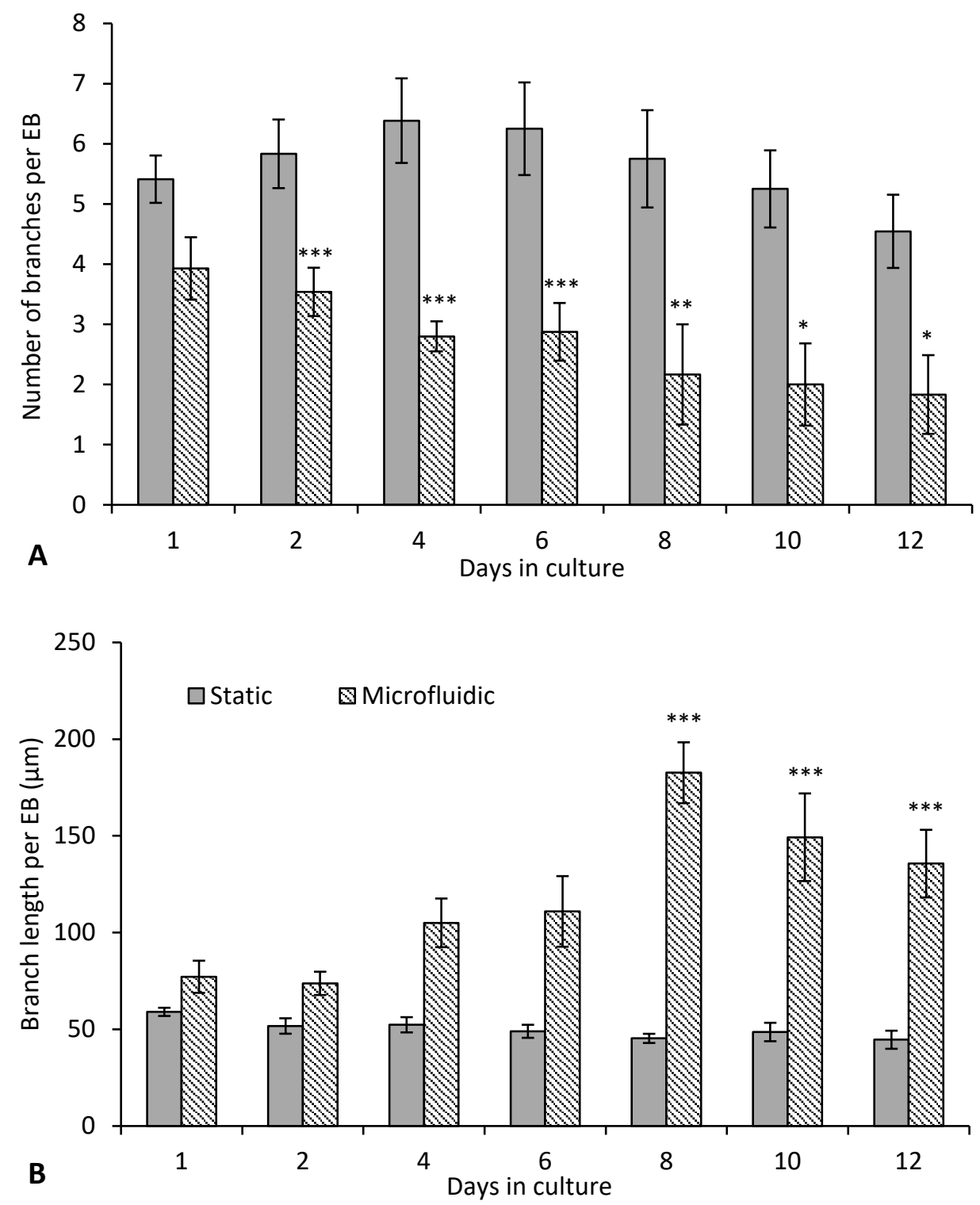

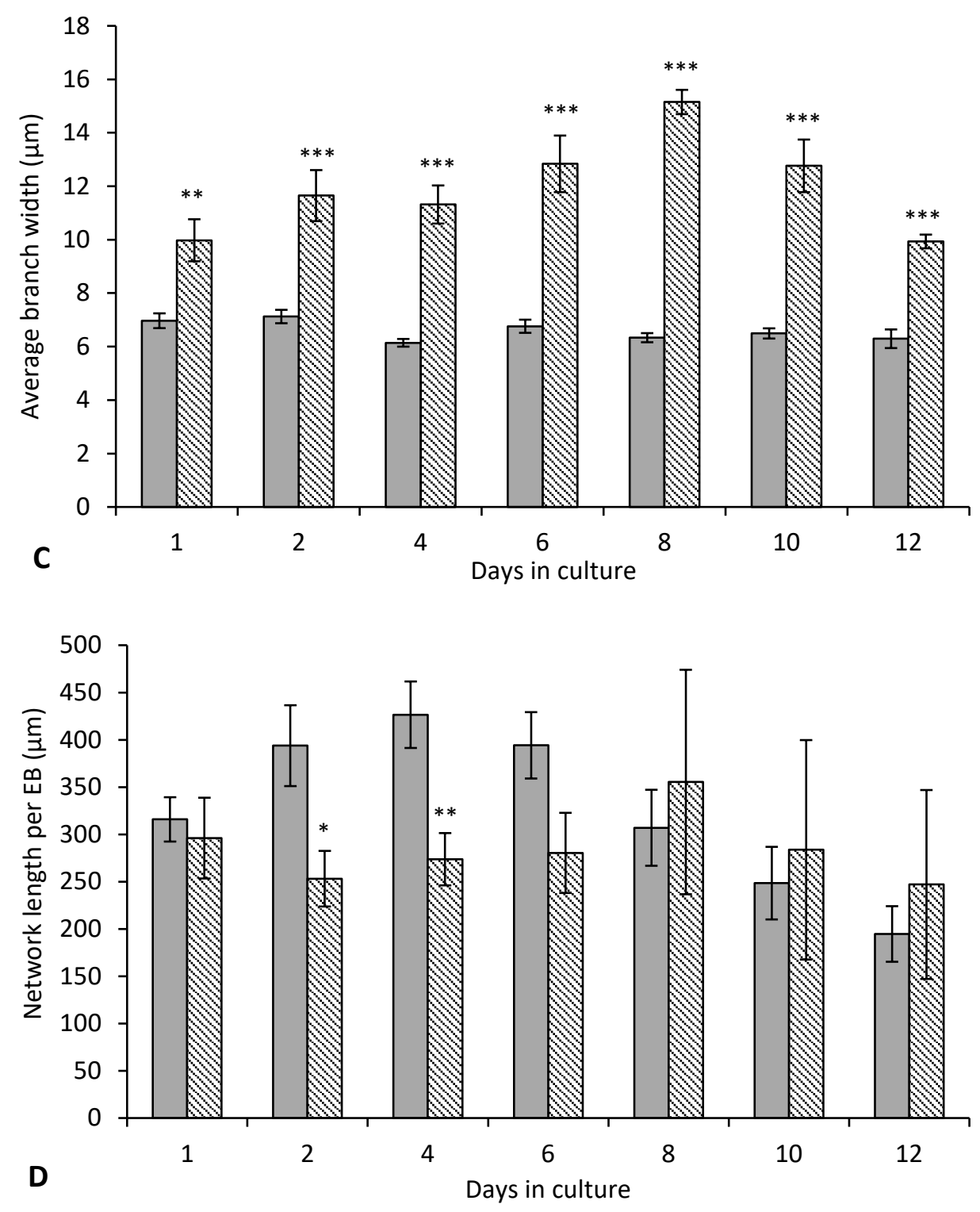

Figure 4. Parameters of $k d r l: G F P^{+}$cell networks in 3D Collagen type-I + Geltrex ${ }^{\mathrm{TM}}+$ Fibrin matrix with or without microfluidic flow. (A) Number of $k d r l: G F P^{+}$branches per EB at different time-points. (B) Average branch length per EB. (C) Average width of $k d r l: G F P^{+}$ branches per EB. (D) Total length of $k d r l: G F P^{+}$cell network per EB. The graphs show significantly higher $k d r l: G F P^{+}$branch length (B) and width (C) in microfluidic culture. Number of observations were 12 for static and eight for microfluidic culture. Error bars represent standard error. $(* * *, \mathrm{p}<.001, * *, \mathrm{p}<.01, *, \mathrm{p}<.05)$.

\subsubsection{Connectedness of kdrl:GFP ${ }^{+}$cell networks in 3D EB culture}

The connectedness of $k d r l: G F P^{+}$cell networks in 3D culture was significantly higher under static conditions compared to microfluidic culture (Figure 5). The network connectedness remained similar from day 1 until day 8 in static culture; however, after day 8 the network started to break down, and connectivity became reduced $(p<0.001)$. In microfluidic culture the network was less connected, having more end points compared to junctions. As the 
$k d r l: G F P^{+}$average branch length in the microfluidic culture increased with time, the network connectivity gradually declined. On day 12 of culture no significant difference was observed in network connectedness between the static and microfluidic cultures.

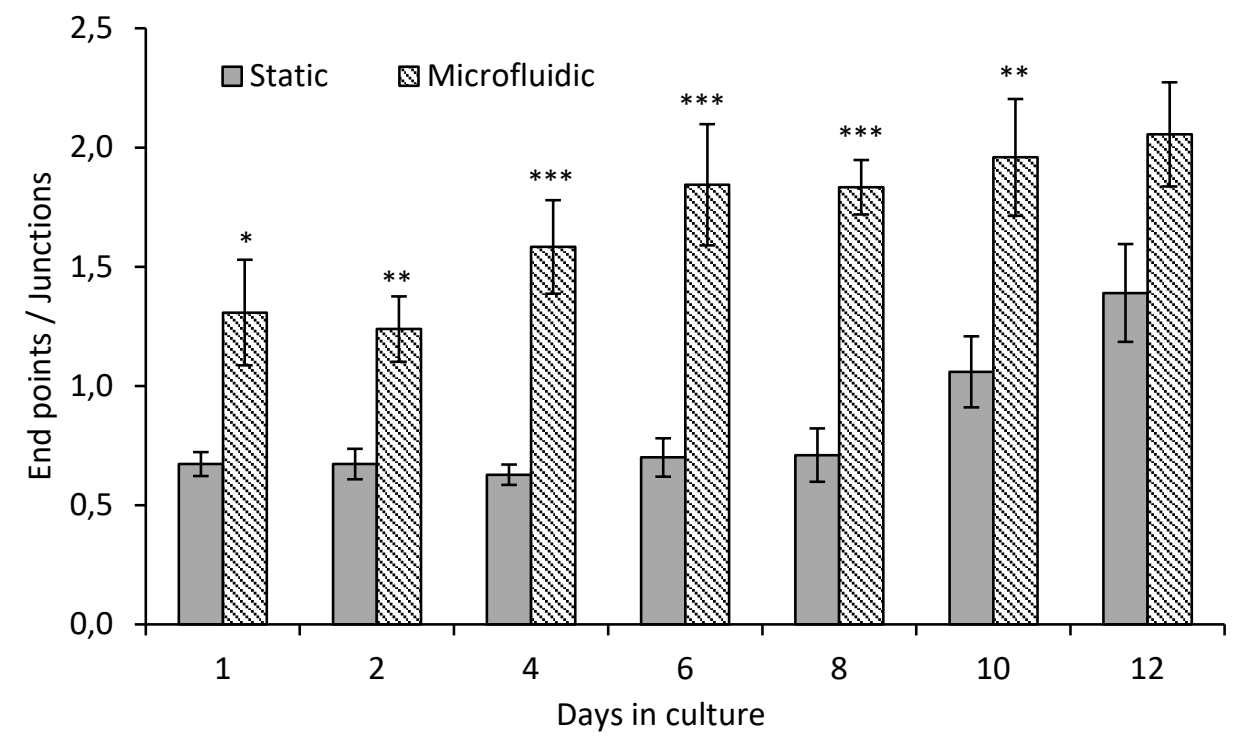

Figure 5. Connectedness of $k d r l: G F P^{+}$cell network in 3D cultures. Values near to zero on the vertical axis indicate a well-connected network. The graph shows that there is formation of a well-connected network in static culture compared to microfluidic culture. Number of observations were 12 for static and eight for microfluidic culture. Error bars represent standard error. $(* * *, \mathrm{p}<.001, * *, \mathrm{p}<.01, *, \mathrm{p}<.05)$.

\subsection{General characteristics of liver explant cultures}

The liver explants isolated from $5 \mathrm{dpf}$ zebrafish larvae already showed a $k d r l: G F P^{+}$vascular network at day 0 (Figure 6). This network changed over time in culture. The kdrl:GFP+ cells covered the surface of the explant by day 2 of culture in collagen type-I + Geltrex ${ }^{\mathrm{TM}}+$ fibrin matrix (Figure 6). At this time-point short strands of $k d r l: G F P^{+}$cells, sprouting from the explant were also observed. However, by day 4 these sprouts were retracted into the explant. Bay day 6 of culture the layer of $k d r l: G F P^{+}$cells covering the explant formed a network-like structure on the surface of the explant (Figure 6). No kdrl:GFP+ sprouts were observed from explants cultured in pure Geltrex ${ }^{\mathrm{TM}}$ substratum.

Day 0

Day 2

Day 4

Day 6 

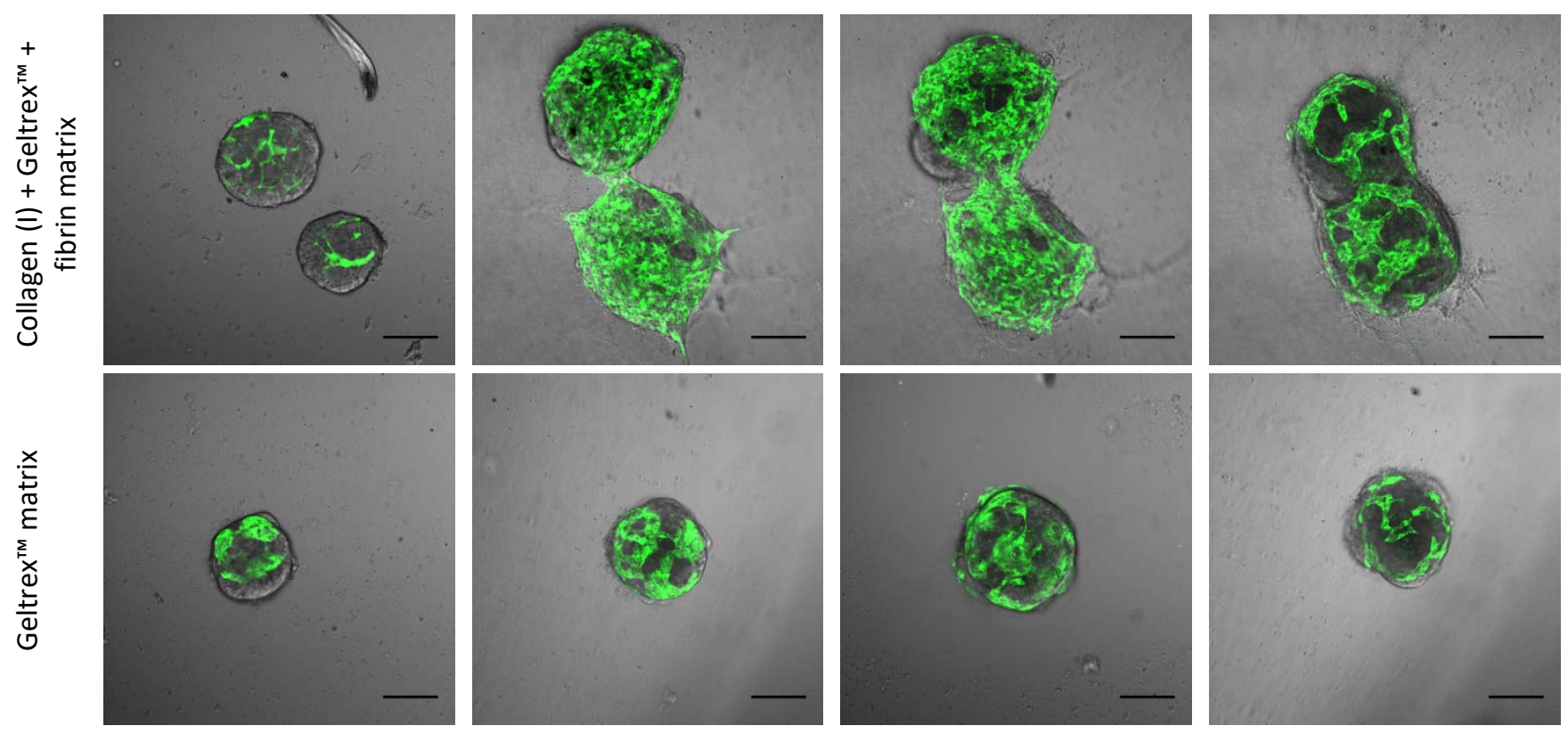

Figure 6. Culture of liver explants isolated from $5 \mathrm{dpf} k d r l$ :GFP zebrafish larvae. Cells with green fluorescence are putative

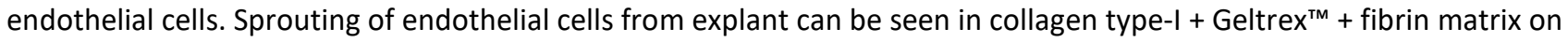
day 2 of culture. In Geltrex ${ }^{\mathrm{TM}}$ matrix the $k d r l: G F P^{+}$cells remained inside or on the surface of the explant. Scale bar, $100 \mu \mathrm{m}$.

\subsubsection{Measurements of kdrl:GFP+ cell network in liver explant culture}

The area covered by $k d r l: G F P^{+}$cell networks per liver explant increased within the first two days of culture (Figure 7A) and decreased after day 4. No significant differences in the $k d r l: G F P^{+}$area per explant were observed between the two substrates tested. The sprouting of the $k d r l: G F P^{+}$cells was observed only in collagen type-I + Geltrex ${ }^{\mathrm{TM}}+$ fibrin substratum. On average, 1.2 sprouts were counted per explant on day 2, with an average length of $18.4 \mu \mathrm{m}$

(Figure 7B and C). However, these sprouts gradually reduced in length and number with time and almost disappeared by day 6 of culture. 

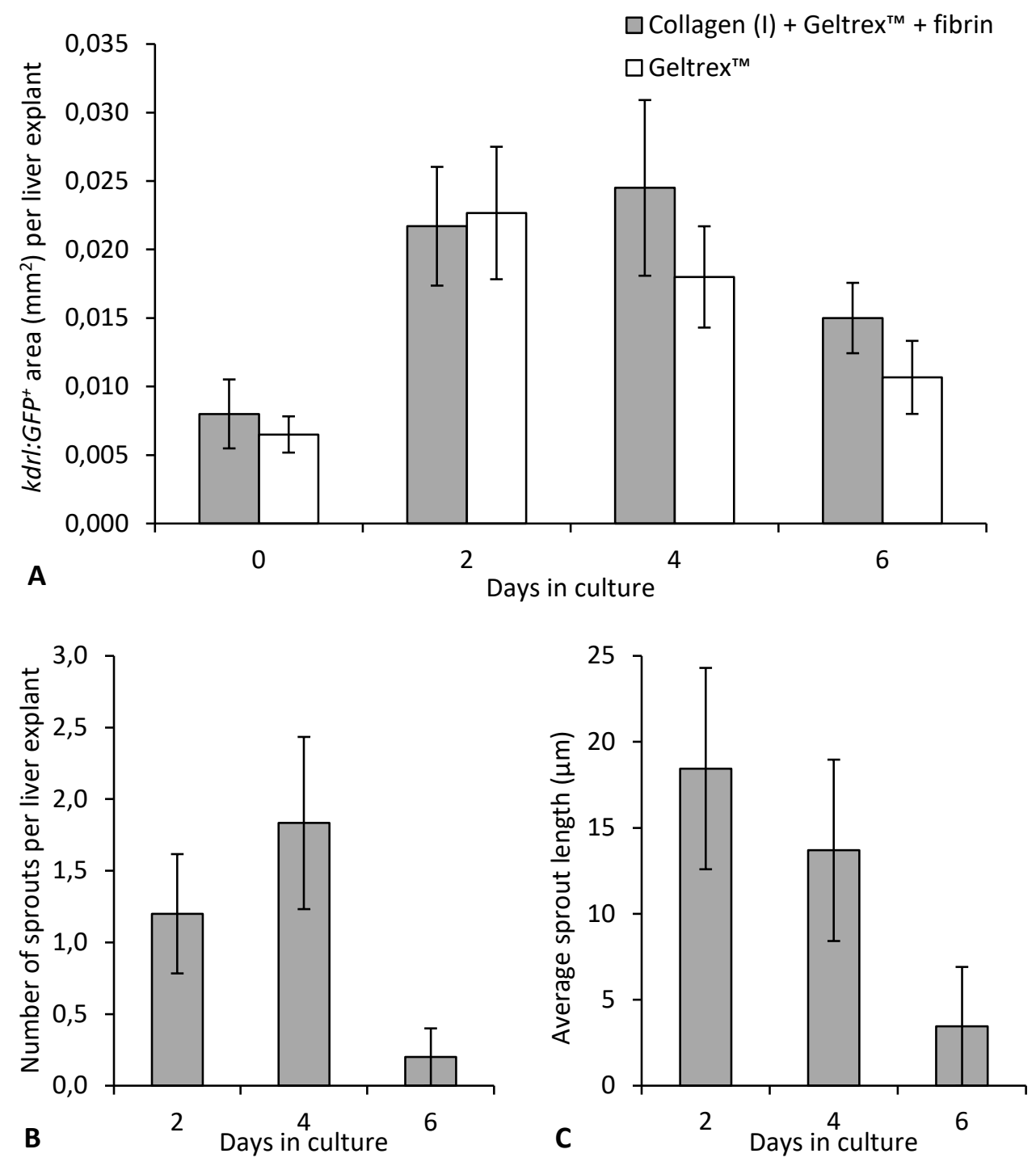

Figure 7. Quantification of area covered by $k d r l: G F P^{+}$cells in liver explant cultures overtime. (A) Change in total area covered by $k d r l: G F P^{+}$cells per explant in the two gel matrices. (B, C) Data from cultures in collagen type-I + Geltrex ${ }^{\mathrm{TM}}+$ fibrin matrix. (B) The average number of $k d r l: G F P^{+}$cell sprouts per explant. (C) Average sprout length per explant. Number of observations were six for collagen type-I + Geltrex ${ }^{\mathrm{TM}}+$ fibrin matrix and four for Geltrex ${ }^{\mathrm{TM}}$ matrix. Error bars represent standard error.

\subsubsection{Liver cell culture on $2 D$ substrate}

On average $120,457 \pm 5,571$ cells were obtained by trypsinizing 100 livers. To establish cellular contact in culture 20,000 cells were plated per well of the CS16-chambered coverglass plate (surface area of each well: $0.34 \mathrm{~cm}^{2}$ ). Therefore, cells obtained from one batch of 100 livers were distributed in six wells, with each substrate composition replicated in two wells. The liver cells isolated contained $8.6 \pm 0.6 \% \mathrm{kdrl}: G F P^{+}$endothelial cells (Figure 8A). The $k d r l: G F P^{+}$cells combined to form small colonies surrounded by $k d r l: G F P^{-}$cells on collagen type-I + Geltrex ${ }^{\mathrm{TM}}+$ fibrin substratum, on day 2 of culture (Figure 8B). 
By day 3 of culture, the colonies of $k d r l: G F P^{+}$endothelial cells appeared to increase in size

(Figure 8C). These colonies connected to each other to form longer blood vessel-like

structures on day 4 of culture (Figure 8D). These vessel-like structures could be observed

also on day 6 of culture (Figure 8E). However, on day 8 on collagen type-I + Geltrex ${ }^{\mathrm{TM}}+$ fibrin

substratum, the culture formed a large clump of cells with a vascular network within (Figure

$8 F)$. This clump of cells was observed to form earlier when the cells had been plated onto

collagen type-I + Geltrex ${ }^{\mathrm{TM}}$ (Figure $8 \mathrm{G}$ ) and pure Geltrex ${ }^{\mathrm{TM}}$ (Figure $8 \mathrm{H}$ ) substrates, or when

plated on uncoated glass substrates (Figure 8I).
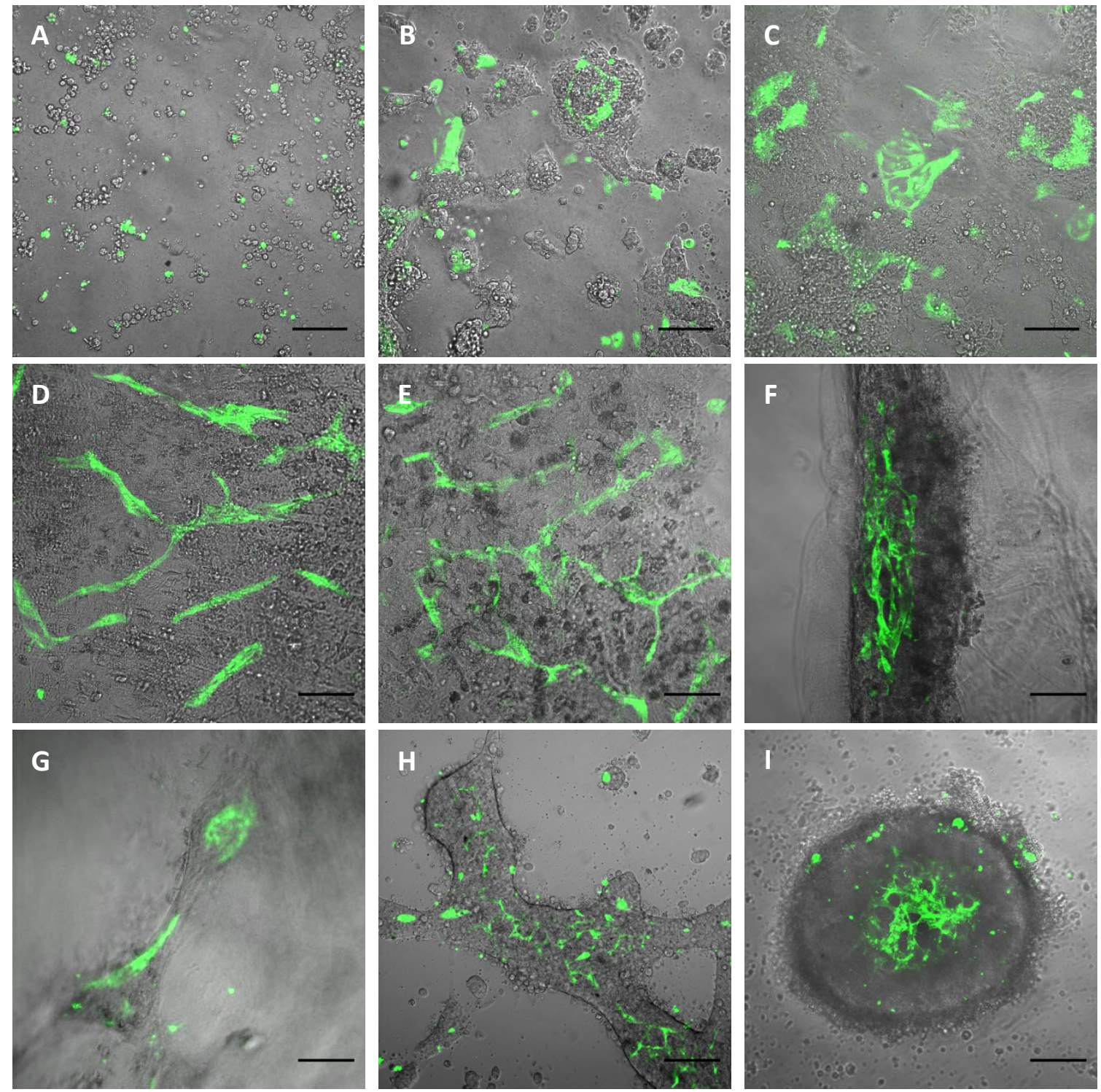

Figure 8. Development of vascular network-like structures in cell cultures derived from $5 \mathrm{dpf}$ zebrafish liver cells. (A-F) Trypsinized liver cells cultured on collagen type-I + Geltrex ${ }^{\mathrm{TM}}+$ fibrin substratum. (A) Liver cells after plating on day 0 of culture, showing rounded $k d r l: G F P^{+}$cells. (B) Day 2 of culture: The cells form colonies of $k d r l: G F P^{+}$cells, surrounded by $k d r l: G F P^{-}$liver cells. (C) Day 3 of culture: The $k d r l: G F P^{+}$cells attain an elongated shape and the colonies appear to increase in size. (D) Network formation of $k d r l: G F P^{+}$cells on day 4 of culture. (E) The $k d r l: G F P^{+}$cell network maintained until day 6 of culture. (F) The whole culture has started to condense into one large aggregate dragging with it the 
substratum, on day 8 of culture. The vascular network remains inside the aggregate. (G) On collagen type-I + Geltrex ${ }^{\mathrm{TM}}$ substratum the liver cells form large colonies, by day 4 of culture, with networks of $k d r l: G F P^{+}$cells formed inside. (H) A similar colony formation of liver cells with $k d r l: G F P^{+}$cell network on day 4 of culture on Geltrex ${ }^{\mathrm{TM}}$ substratum. (I) Without extra substrate coating, the liver cells form large 3D aggregates with a $k d r l: G F P^{+}$cell network within 4 days of culture. Scale bar, $100 \mu \mathrm{m}$. A - F show the same field.

\subsection{Heart explant and dissociated cell culture}

The heart explants cultured in 3D collagen type-I + Geltrex ${ }^{\mathrm{TM}}+$ fibrin matrix showed sprouting of $k d r l: G F P^{+}$putative endothelial cells on day 2 (Figure 9A). However, these sprouts almost disappeared on day 4 of culture (Figure 9B). A quantitative analysis of the heart explant cultures showed a significant reduction in the total $k d r l: G F P^{+}$area per explant on day 6 compared to day 2 (Figure 9C). The number of sprouts per explant (Figure 9D) and the average sprout length (Figure 9E) also became reduced from day 2 to day 4 .
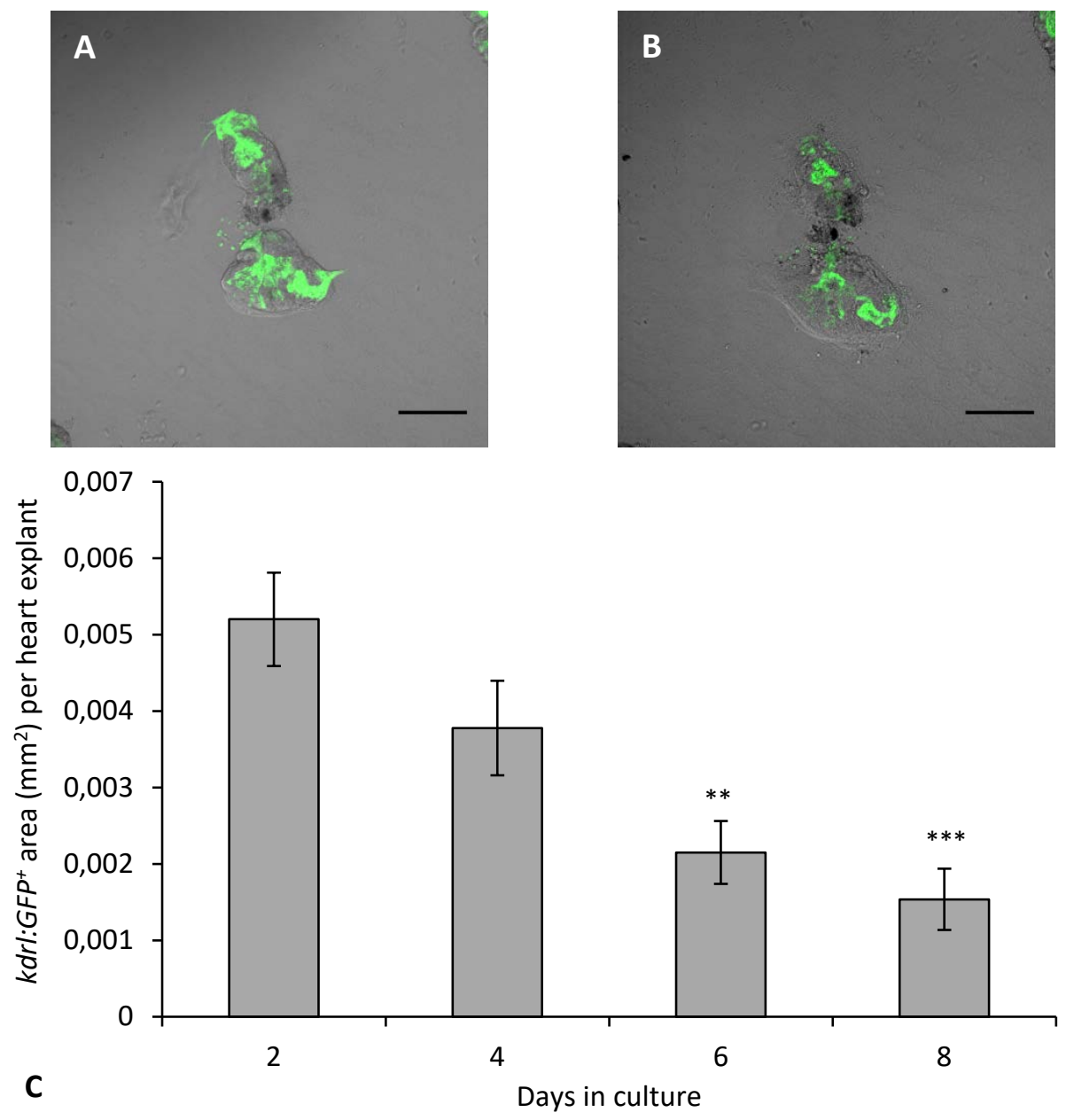

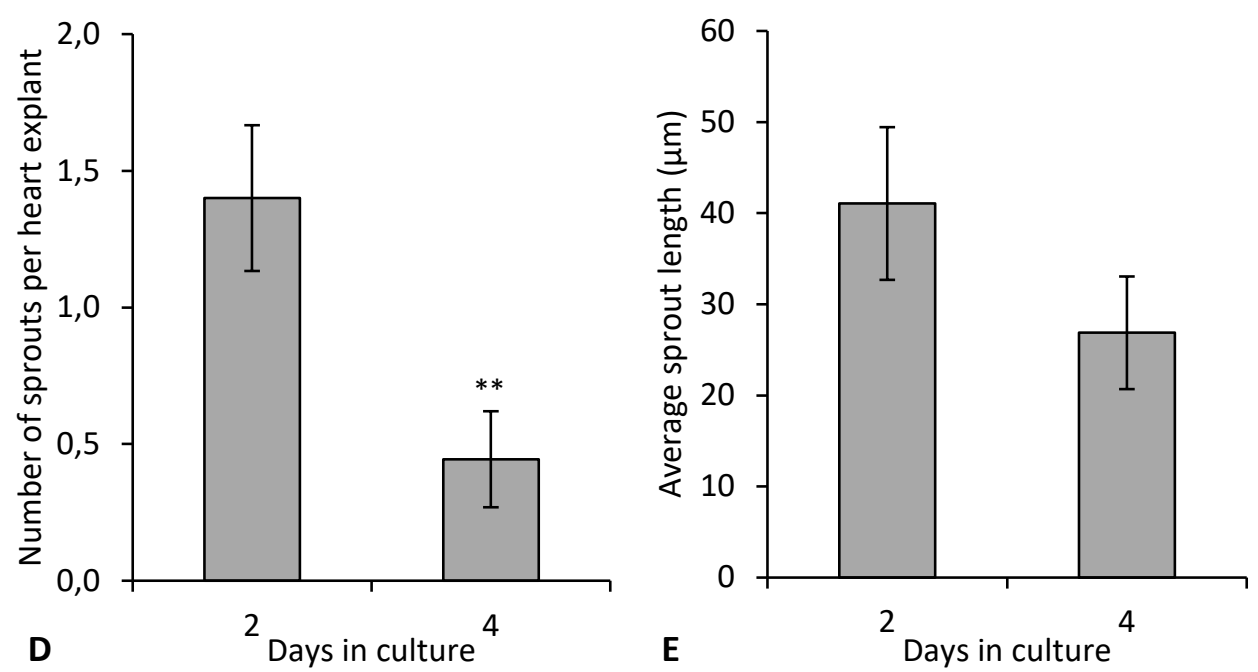

Figure 9. Sprouting of $k d r l: G F P^{+}$cells from heart explant cultured in collagen type-I + Geltrex ${ }^{\mathrm{TM}}+$ fibrin matrix. (A) The heart explant showing $k d r l: G F P^{+}$sprouts in the surrounding matrix on day 2 of culture. (B) The sprouts retracted by day 4 of culture with $k d r l: G F P^{+}$cells remaining inside the explants. (C) Total area covered by kdrl:GFP+ cells per heart explant overtime. (D) Number of $k d r l: G F P^{+}$sprouts per explant. (E) Average sprout length per explant. Scale bar for $\mathbf{A}$ and $\mathbf{B}, 100 \mu \mathrm{m}$. Number of observations were six for $\mathbf{C}, \mathbf{D}$ and $\mathbf{E}$. Error bars represent standard error. $\left({ }^{* * *}, \mathrm{p}<.001\right.$, **, $\mathrm{p}<.01$ compared to values on day 2 )

The embryonic hearts were difficult to trypsinize in the preliminary experiments; we therefore adopted liberase TL enzyme to dissociate them. On average, 42,353 $\pm 1,707$ cells were isolated from 100 hearts, and the cell suspension contained $28.3 \pm 1.0 \% \mathrm{kdrl}: G F P^{+}$ endothelial cells. On fibronectin substratum the $k d r l: G F P^{+}$cells showed an elongated morphology $24 \mathrm{~h}$ after plating (Figure 10A). Other heart cells that were mostly rounded were removed from culture at this stage by washing with medium, and the colonies of $k d r l: G F P^{+}$ cells were maintained on fresh medium. However, these colonies could not be maintained longer and their size reduced with culture duration (Figure 10B and C). Only a few cells were found in culture on day 5 (image not shown).
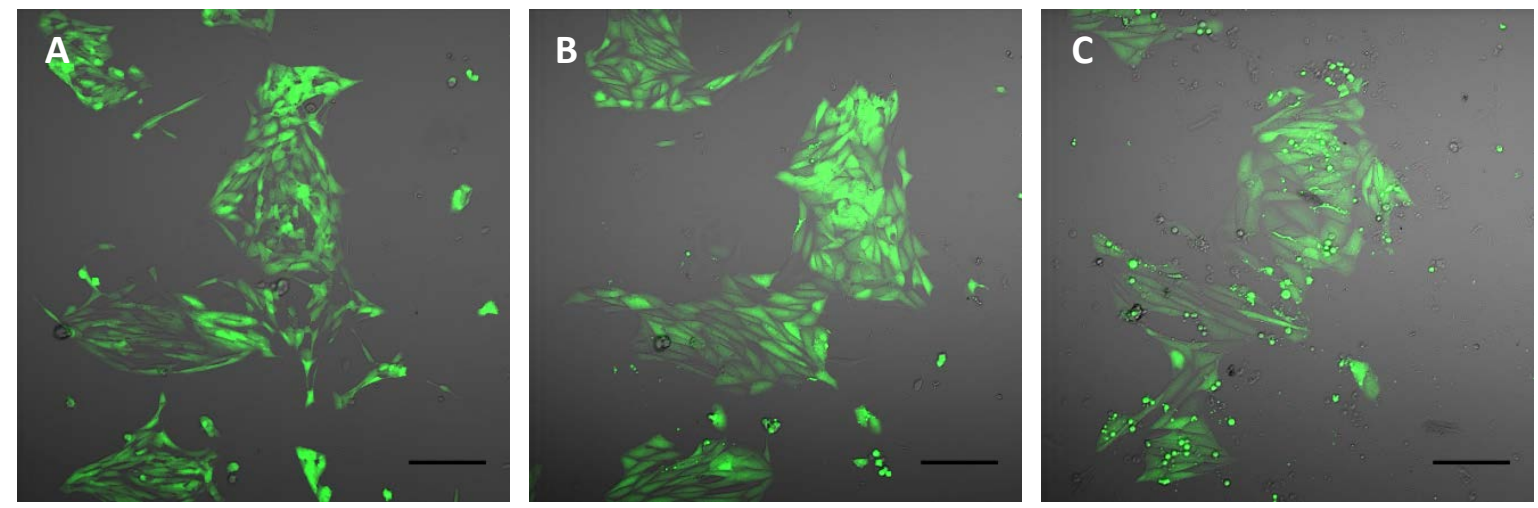

Figure 10. Colony formation of $k d r l: G F P^{+}$cells in dissociated heart cell culture. (A) The $k d r l: G F P^{+}$cells attached to the fibronectin substratum on day 1 of the culture. The unattached heart cells were washed out. (B) The colony of $k d r l: G F P^{+}$cells appear to shrink in size by day 2 of culture. (C) Further reduction in 
size of the colony with rounded, detaching cells can be seen on day 4 of culture. scale bar, $100 \mu \mathrm{m}$.

\section{Discussion}

\subsection{Choice of embryonic stage}

For EB culture the cells isolated from blastocyst stage embryos ( $3.5 \mathrm{hpf}$ ) were used. The embryos at this stage contain pluripotent cells, and lineage segregation can be modulated by varying the culture conditions [67]. Techniques have been developed previously for the aseptic isolation and culture of zebrafish blastocyst cells [65]. However, little is known about the differentiation events and culture strategies needed for the lineage-specific differentiation of these cells.

For embryonic liver and heart tissue culture, zebrafish embryos at an early larval stage (5 dpf) were used. At this stage, there is relatively little yolk remaining in the larva. This makes it easier to isolate the liver, which is more hidden by the yolk in earlier stages. We found that, at $5 \mathrm{dpf}$, the tissues isolated from 100 larvae contained sufficient numbers of cells to allow for replicates. Zebrafish larvae up to $5 \mathrm{dpf}$ do not engage in exogenous feeding but rely instead on yolk nutrients; therefore, it is easier to keep them sterile in closed Petri dishes. Furthermore, at this stage the tissues presumably contain more precursor cells, with the potential to grow and differentiate, compared to the tissues of more advance stages.

\subsection{EB culture in microfluidic setup}

Mouse EB cultures can undergo the formation of blood islands and vascular morphogenesis [29]. In our study, the zebrafish EBs developed in hanging drop culture, also show some degree of vascular organization, i.e. a well-connected radial network inside the EBs. However, when the EBs were transferred to 3D culture, the radial pattern and connectivity of the network was lost due to the extension of the vascular sprouts into the surrounding matrix.

Vascular sprouting is a physiological process in which selection of endothelial tip cells, as well as migration and vascular extension, occurs in existing blood vessels in response to angiogenic stimuli [68]. The phenomenon of vascular sprouting has been previously reported in mouse EB cultures [38]. Similarly, we also observed angiogenic sprouting in our zebrafish EB cultures; however, the extent of sprouting was less compared to the mouse model. This 
may because we used primary blastocyst cells to establish EB cultures, while mouse embryonic stem cell lines, which are adapted to proliferation in vitro, have been used in the other studies. Previous studies on zebrafish primary blastocyst cell culture have reported high cell death rates and low proliferative capacity in these cells [69]; this may explain the low level of sprouting in our cultures.

Studies on mouse EBs in vitro, and zebrafish embryos in vivo, have shown the directional migration of vascular sprouts towards the highest concentration of VEGF [70]. In our EB cultures, the selection of tip cells and the direction of sprout extension appeared to be random. This may because of the presence of angiogenic stimuli (growth factors) dispersed throughout the medium. However, we observed in some cases the extension of sprouts from one EB in the direction of a nearby EB. This may correlate with the in vivo situation in which the release of angiogenic growth factors from a distant cell population directs the migration of vascular sprouting.

The EB cultures described here with $k d r l: G F P^{+}$sprouts were maintained under microfluidic conditions for a maximum of 12 days. In our previous studies, the growth of EB cultures could be maintained for longer time in primary culture, as well as in subculture [71]. However, the percentage of $k d r l: G F P^{+}$cells in those cultures dropped significantly because they became overgrown by fibroblast-like cells [71]. Furthermore, the regression of $k d r l: G F P^{+}$ sprouts was observed after day 6 in our static cultures described here. These results are in accordance with a study of angiogenic sprouting in mouse EB cultures, in which the cells continued to degrade the 3D matrix after 12 days of culture, and differentiate into a variety of cells, making it difficult to interpret the vascular sprouts [72].

The medium was refreshed in our static culture at four day intervals. This interval was chosen after our preliminary studies indicated that cell growth was hindered after four days in non-replacement cultures. By contrast, the microfluidic cultures continued to grow with recycling of the medium. Medium replacement at four day intervals in the static culture may not be ideal for screening drugs or molecules that have a short half-life. For those experiments, shorter interval between the medium refreshment may be needed.

It is possible that the microfluidic system described here can be adapted for toxicity screening. For this purpose, the molecules to be tested can be easily added to the medium 
reservoir. Depending on the exposure time, the final volume of the medium in the reservoir can be adjusted according to the flow rate $(20 \mu \mathrm{L} / \mathrm{min}$ in our case). Once the medium is withdrawn through the culture chamber, the reservoir can be refilled with fresh medium and the exhausted medium discarded or used for further analysis.

In the experiments described here, we formed a 3D gel matrix containing zebrafish EBs in a microfluidic channel slide. The open design of the microfluidic channel allows direct contact at the interface between the matrix and the medium. This is different to the microfluidic systems currently used for 3D cell culture, in which the medium can only diffuse into the matrix [73-76]. One of the drawbacks with the latter systems is that they do not mimic the dynamic environment of the tissue, but represent a rather static condition [43]. The flow of medium around the 3D matrix in our system presumably exerted a shear stress on the EB cells inside the matrix and allowed the extension of $k d r l: G F P^{+}$sprouts.

Under physiological conditions, endothelial cells produce secreted factors in response to the shear stress induced by the blood flow [42]. These factors are essential for the development, regulation and maintenance of the blood vessels [42]. In a microfluidic culture, the flow rate of the medium is critical for cell proliferation, viability and function [77]. This was observed in our microfluidic cultures where the $k d r l: G F P^{+}$cells failed to form networks at low flow rates ( 2 and $10 \mu \mathrm{L} / \mathrm{min}$ ). One possible explanation for this could be poor viability of cells at such low flow rates. Thus, under these low flow rates the $k d r l: G F P^{+}$cells were mostly rounded in shape compared to $20 \mu \mathrm{L} / \mathrm{min}$ flow rate, where the cells acquired an elongated shape and formed connected networks.

One of the challenges with our microfluidic culture was to find a balance between the flow rate of the medium and the mechanical stability of the 3D matrix. The gel matrices comprising lower concentrations of collagen type-I $(1.5 \mathrm{mg} / \mathrm{mL})$ and fibrin $(1 \mathrm{mg} / \mathrm{mL})$ were not mechanically stable at the $20 \mu \mathrm{L} / \mathrm{min}$ flow rate required for network formation. When the concentrations of the above mentioned substrates were increased to $2.5 \mathrm{mg} / \mathrm{mL}$ and 2 $\mathrm{mg} / \mathrm{mL}$, respectively, the matrix formed was stable at the desired flow rate. Beside the stability of the matrix of higher concentration, the stiffness of the 3D matrix itself is presumably important in the culturing of vascular networks; thus, previous studies have 
shown that stiffness of the matrix promotes the organization of endothelial cells into capillary networks in vitro [78].

In our experiments, the differences between the microfluidic and static cultures was seen mainly in the length and width of $k d r l: G F P^{+}$strands. In general, network formation by $k d r l: G F P^{+}$cells in static cultures was limited to the periphery of the EBs. In microfluidic culture by contrast, the $k d r l: G F P^{+}$cells extended more into the matrix and formed longer branches. A possible explanation for this may be that the shear stress causes the cells to secrete factors (as discussed above) which modulate the surrounding matrix and allow the cells to grow further into the matrix. The wider diameter of $k d r l: G F P^{+}$strands in microfluidic cultures may indicate the formation of blood vessel-like structures with a lumen. By contrast, in the static cultures, the thinner branches formed are more consistent with a solid chain of cells connected end-to-end than with a continuous vessel.

A network having fewer end points and more junctions is considered to be a well-connected network [22]. The connectedness of a network can be determined by dividing the number of endpoints by the number of junctions [22]. We find that the connectedness of the networks depends on whether the network is more confined (as in the static culture) or spread (as in the microfluidic culture). In principle, the more confined network will be well-connected compared to a network with longer branches. In the microfluidic cultures in our experiments, as the branch length increased, the network connectivity was lost.

\subsection{Culture of embryonic liver and heart tissues}

The zebrafish liver and heart explant cultures described here might be suitable for development as alternative to mouse aortic ring culture for sprouting angiogenesis. One possible application of these explants could be to test the stimulatory or inhibitory effect of various substances on angiogenesis. Mouse aortic ring cultures are currently being used for such studies $[79,80]$. Variability between cultures remains an issue with the mouse aortic ring model [14]. Although we found variability in the explants isolated from zebrafish embryos, the zebrafish model can easily yield a large more number of explants which may help minimise this issue The small size of zebrafish embryos makes it technically difficult to dissect the embryos for tissue isolation. However, with practice, we were able to isolate tissues from 100 embryos in approximately three hours. 
Under standard conditions, zebrafish embryos hatch at $48 \mathrm{hpf}$ [53]. We found it important to decontaminate the embryos before hatching (at $24 \mathrm{hpf}$ ), because preliminary experiments showed that explants, isolated from the embryos decontaminated after hatching at $5 \mathrm{dpf}$, could not be maintained free from contamination in culture. We also found that embryos treated with sodium hypochlorite at $24 \mathrm{hpf}$ have greatly impaired hatching; it is therefore necessary to manually dechorionate these embryos before sealing them into the Petri dish. Using this procedure the tissues isolated from these embryos at $5 \mathrm{dpf}$ were successfully maintained sterile in culture.

The sprouting of $k d r l: G F P^{+}$cells from liver explants could only be observed in matrices composed of collagen type-I, Geltrex ${ }^{\mathrm{TM}}$ and fibrin. Explants cultured in pure Geltrex ${ }^{\mathrm{TM}}$ matrix did not show any sprouting. These results are in accordance with mouse aortic ring cultures which have been shown to produce higher microvessel sprouting in collagen type-l and fibrin matrices compared to Matrigel ${ }^{\mathrm{TM}}$ [81]. The Geltrex ${ }^{\mathrm{TM}}$ we used in our experiments is similar to Matrige $^{\mathrm{TM}}$, and is a mixture of laminin, collagen type-IV, entactin and heparin sulphate proteoglycans (manufacturer's documentation).

Similar to microvessel formation in mouse aortic ring culture [81], the dimensions of the network-like structure formed by $k d r l: G F P^{+}$cells in trypsinized liver cells cultured on pure Geltrex $^{\mathrm{TM}}$ substratum were thinner and different from the much broader networks formed on collagen type-I + Geltrex ${ }^{\mathrm{TM}}+$ fibrin substratum. The sprouting of $k d r l: G F P^{+}$cells in our explant cultures was observed on day 2 which is earlier than in the mouse aortic ring culture, where the peak sprouting of microvessels is reported to take place on day 6 of culture [81]. Regression of the sprouts from the explants occurred on day 4 in our experiments, whereas in mouse aortic ring culture this phenomena occurs on day 9 of culture [81].

The average length of the $k d r l: G F P^{+}$cell sprouts emerging from the heart explants was higher compared to the liver explants ( $41.1 \pm 8.4 \mathrm{vs} 18.4 \pm 5.8 \mu \mathrm{m})$. This may be because of a higher percentage of $k d r l: G F P^{+}$cells in the isolated hearts compared to the livers, as indicated by our quantification of the cell isolates of these tissues. The colonies of kdrl:GFP+ cells in the dissociated heart cell culture could not be maintained longer, probably due to low seeding density. 


\section{Conclusions}

Zebrafish embryoid body culture is a promising model for in vitro vasculogenesis and angiogenesis. Microfluidic flow seems to have an effect on the growth of blood vessels in EB culture. The use of a complex extracellular matrix with fibrin as a crucial part was, in our hands, optimal for culturing vascular networks. The zebrafish liver and heart explant cultures are promising models for sprouting angiogenesis. More experiments are needed to optimize the substrate and medium composition for these cultures so that the cultures can be expanded and be maintained for longer periods. This goal may also require co-culture with other cell- or tissue-types. In principle, pure populations of viable kdrl:GFP+ ${ }^{+}$cells could also be isolated from these cultures using fluorescence activated cell sorting assay. These cells could then be used for further analysis (e.g. gene expression profiling), as wells as for coculturing with the EBs to improve the formation of vascular networks.

\section{Acknowledgements}

We would like to thank Prof. Stefan Schulte-Merker (Institute for Cardiovascular Organogenesis and Regeneration, Westfalische Wilhelms University, Munster, Germany) for providing the zebrafish $k d r l: G F P$ line for this research.

This work was supported by the Smart Mix programme of the Netherlands Ministry of Economic Affairs and the Netherlands Scientific Research Council (NWO)[grant number SSM06010]; and the Generade programme of the Centre of Expertise Genomics in Leiden, The Netherlands[grant number 2016_004].

\section{References}

[1] M.B. Fisher, R.L. Mauck, Tissue engineering and regenerative medicine: recent innovations and the transition to translation, Tissue engineering. Part B, Reviews 19(1) (2013) 1-13.

[2] S.N. Bhatia, D.E. Ingber, Microfluidic organs-on-chips, Nat Biotechnol 32(8) (2014) 76072.

[3] Y. Haraguchi, T. Shimizu, M. Yamato, T. Okano, Concise review: cell therapy and tissue engineering for cardiovascular disease, Stem cells translational medicine 1(2) (2012) 136-41. [4] A. Hansen, A. Eder, M. Bonstrup, M. Flato, M. Mewe, S. Schaaf, B. Aksehirlioglu, A.P. Schwoerer, J. Uebeler, T. Eschenhagen, Development of a drug screening platform based on engineered heart tissue, Circ Res 107(1) (2010) 35-44. 
[5] J.R. Levick, The microcirculation and solute exchange, An Introduction to cardiovascular physiology, Taylor \& Francis2010, pp. 166-187.

[6] R.Y. Kannan, H.J. Salacinski, K. Sales, P. Butler, A.M. Seifalian, The roles of tissue engineering and vascularisation in the development of micro-vascular networks: a review, Biomaterials 26(14) (2005) 1857-75.

[7] G. Vunjak-Novakovic, D.T. Scadden, Biomimetic platforms for human stem cell research, Cell stem cell 8(3) (2011) 252-61.

[8] M. Ibrahim, M.K. Richardson, Microfluidic Devices for Cell, Tissue and Embryo Culture, Recent Patents on Regenerative Medicine 3(3) (2013) 249-263.

[9] T. Zou, J. Fan, A. Fartash, H. Liu, Y. Fan, Cell-based strategies for vascular regeneration, J Biomed Mater Res A 104(5) (2016) 1297-314.

[10] K. Shan, C.P. Li, C. Liu, X. Liu, B. Yan, RNCR3: A regulator of diabetes mellitus-related retinal microvascular dysfunction, Biochem Biophys Res Commun (2016).

[11] L.C. Roudsari, J.L. West, Studying the influence of angiogenesis in in vitro cancer model systems, Adv Drug Deliv Rev 97 (2016) 250-9.

[12] M.S. Azimi, M. Lacey, D. Mondal, W.L. Murfee, An Ex Vivo Tissue Culture Model for Antiangiogenic Drug Testing, Methods Mol Biol 1464 (2016) 85-95.

[13] N. Vargesson, Thalidomide-induced teratogenesis: history and mechanisms, Birth Defects Res C Embryo Today 105(2) (2015) 140-56.

[14] C.A. Staton, M.W. Reed, N.J. Brown, A critical analysis of current in vitro and in vivo angiogenesis assays, International journal of experimental pathology 90(3) (2009) 195-221.

[15] M.P. Lutolf, J.A. Hubbell, Synthetic biomaterials as instructive extracellular microenvironments for morphogenesis in tissue engineering, Nat Biotechnol 23(1) (2005) 4755.

[16] M.N. Nakatsu, R.C. Sainson, J.N. Aoto, K.L. Taylor, M. Aitkenhead, S. Perez-del-Pulgar, P.M. Carpenter, C.C. Hughes, Angiogenic sprouting and capillary lumen formation modeled by human umbilical vein endothelial cells (HUVEC) in fibrin gels: the role of fibroblasts and Angiopoietin-1, Microvasc Res 66(2) (2003) 102-12.

[17] V.M. Delgado, L.G. Nugnes, L.L. Colombo, M.F. Troncoso, M.M. Fernandez, E.L. Malchiodi, I. Frahm, D.O. Croci, D. Compagno, G.A. Rabinovich, C. Wolfenstein-Todel, M.T. Elola, Modulation of endothelial cell migration and angiogenesis: a novel function for the "tandem-repeat" lectin galectin-8, FASEB J 25(1) (2011) 242-54.

[18] J. Zhu, W. Cui, X. Liu, J. Ying, C. Hu, Y. Zhang, In vitro and ex vivo angiogenic effects of roxarsone on rat endothelial cells, Toxicol Lett 223(2) (2013) 175-82.

[19] I. Arnaoutova, H.K. Kleinman, In vitro angiogenesis: endothelial cell tube formation on gelled basement membrane extract, Nat Protoc 5(4) (2010) 628-35.

[20] P. Allen, J. Melero-Martin, J. Bischoff, Type I collagen, fibrin and PuraMatrix matrices provide permissive environments for human endothelial and mesenchymal progenitor cells to form neovascular networks, J Tissue Eng Regen Med 5(4) (2011) e74-86.

[21] S. Kusuma, Y.I. Shen, D. Hanjaya-Putra, P. Mali, L. Cheng, S. Gerecht, Self-organized vascular networks from human pluripotent stem cells in a synthetic matrix, Proc Natl Acad Sci U S A 110(31) (2013) 12601-6.

[22] M.L. Moya, Y.H. Hsu, A.P. Lee, C.C. Hughes, S.C. George, In vitro perfused human capillary networks, Tissue Eng Part C Methods 19(9) (2013) 730-7.

[23] S. Kim, H. Lee, M. Chung, N.L. Jeon, Engineering of functional, perfusable 3D microvascular networks on a chip, Lab Chip 13(8) (2013) 1489-500. 
[24] D.H. Nguyen, S.C. Stapleton, M.T. Yang, S.S. Cha, C.K. Choi, P.A. Galie, C.S. Chen, Biomimetic model to reconstitute angiogenic sprouting morphogenesis in vitro, Proc Natl Acad Sci U S A 110(17) (2013) 6712-7.

[25] H. Li, J. Chang, Bioactive silicate materials stimulate angiogenesis in fibroblast and endothelial cell co-culture system through paracrine effect, Acta Biomaterialia 9(6) (2013) 6981-6991.

[26] Y. Zheng, J. Chen, M. Craven, N.W. Choi, S. Totorica, A. Diaz-Santana, P. Kermani, B. Hempstead, C. Fischbach-Teschl, J.A. Lopez, A.D. Stroock, In vitro microvessels for the study of angiogenesis and thrombosis, Proc Natl Acad Sci U S A 109(24) (2012) 9342-7.

[27] K. Stamati, J.V. Priestley, V. Mudera, U. Cheema, Laminin promotes vascular network formation in 3D in vitro collagen scaffolds by regulating VEGF uptake, Experimental cell research 327(1) (2014) 68-77.

[28] A.M. Bratt-Leal, R.L. Carpenedo, T.C. McDevitt, Engineering the embryoid body microenvironment to direct embryonic stem cell differentiation, Biotechnol Prog 25(1) (2009) 43-51.

[29] B. Vailhe, D. Vittet, J.J. Feige, In vitro models of vasculogenesis and angiogenesis, Lab Invest 81(4) (2001) 439-52.

[30] A.M. Goodwin, In vitro assays of angiogenesis for assessment of angiogenic and antiangiogenic agents, Microvasc Res 74(2-3) (2007) 172-83.

[31] L. Jakobsson, J. Kreuger, L. Claesson-Welsh, Building blood vessels--stem cell models in vascular biology, J Cell Biol 177(5) (2007) 751-5.

[32] H. Lodish, A. Berk, S.L. Zipursky, P. Matsudaira, D. Baltimore, J. Darnell, Section 6.2 Growth of Animal cells in culture, in: W.H. Freeman (Ed.), Molecular cell biology, New York, 2000.

[33] R.F. Nicosia, The aortic ring model of angiogenesis: a quarter century of search and discovery, Journal of cellular and molecular medicine 13(10) (2009) 4113-36.

[34] M. Deckers, G. van der Pluijm, S. Dooijewaard, M. Kroon, V. van Hinsbergh, S. Papapoulos, C. Lowik, Effect of angiogenic and antiangiogenic compounds on the outgrowth of capillary structures from fetal mouse bone explants, Laboratory Investigation 81(1) (2001) 5-15.

[35] S. Rezzola, M. Belleri, D. Ribatti, C. Costagliola, M. Presta, F. Semeraro, A novel ex vivo murine retina angiogenesis (EMRA) assay, Experimental eye research 112 (2013) 51-6. [36] S.V. Brodsky, M. Smith, M. Kashgarian, M.S. Goligorsky, A model for ex vivo renal angiogenesis, Nephron. Experimental nephrology 93(1) (2003) e46-52.

[37] R. Rojas-Rodriguez, O. Gealekman, M.E. Kruse, B. Rosenthal, K. Rao, S. Min, K.D. Bellve, L.M. Lifshitz, S. Corvera, Adipose tissue angiogenesis assay, Methods in enzymology 537 (2014) 75-91.

[38] Z. Liu, F. Lebrin, J.A. Maring, S. van den Driesche, S. van der Brink, M. van Dinther, M. Thorikay, S. Martin, K. Kobayashi, L.J. Hawinkels, L.A. van Meeteren, E. Pardali, J. Korving, M. Letarte, H.M. Arthur, C. Theuer, M.J. Goumans, C. Mummery, P. ten Dijke, ENDOGLIN is dispensable for vasculogenesis, but required for vascular endothelial growth factor-induced angiogenesis, PLoS One 9(1) (2014) e86273.

[39] W. Song, C.W. Fhu, K.H. Ang, C.H. Liu, N.A. Johari, D. Lio, S. Abraham, W. Hong, S.E. Moss, J. Greenwood, X. Wang, The fetal mouse metatarsal bone explant as a model of angiogenesis, Nat Protoc 10(10) (2015) 1459-73.

[40] V.V. Masson, L. Devy, C. Grignet-Debrus, S. Bernt, K. Bajou, S. Blacher, G. Roland, Y. Chang, T. Fong, P. Carmeliet, J.M. Foidart, A. Noel, Mouse Aortic Ring Assay: A New 
Approach of the Molecular Genetics of Angiogenesis, Biological procedures online 4 (2002) 24-31.

[41] F.N. Kiefer, V.C. Munk, R. Humar, T. Dieterle, L. Landmann, E.J. Battegay, A versatile in vitro assay for investigating angiogenesis of the heart, Experimental cell research $300(2)$ (2004) 272-82.

[42] P.F. Davies, Hemodynamic shear stress and the endothelium in cardiovascular pathophysiology, Nat Clin Pract Cardiovasc Med 6(1) (2009) 16-26.

[43] N. Gupta, J.R. Liu, B. Patel, D.E. Solomon, B. Vaidya, V. Gupta, Microfluidics-based 3D cell culture models: Utility in novel drug discovery and delivery research, Bioengineering \& Translational Medicine 1(1) (2016) 63-81.

[44] A. Hasan, A. Paul, N.E. Vrana, X. Zhao, A. Memic, Y.S. Hwang, M.R. Dokmeci, A. Khademhosseini, Microfluidic techniques for development of 3D vascularized tissue, Biomaterials 35(26) (2014) 7308-25.

[45] S. Rezzola, M. Belleri, G. Gariano, D. Ribatti, C. Costagliola, F. Semeraro, M. Presta, In vitro and ex vivo retina angiogenesis assays, Angiogenesis 17(3) (2014) 429-42.

[46] W.H. Zhu, M. Iurlaro, A. Maclntyre, E. Fogel, R.F. Nicosia, The mouse aorta model: influence of genetic background and aging on bFGF- and VEGF-induced angiogenic sprouting, Angiogenesis 6(3) (2003) 193-9.

[47] M.N. Chavez, G. Aedo, F.A. Fierro, M.L. Allende, J.T. Egana, Zebrafish as an Emerging Model Organism to Study Angiogenesis in Development and Regeneration, Front Physiol 7 (2016) 56.

[48] R.N. Wilkinson, F.J. van Eeden, The zebrafish as a model of vascular development and disease, Prog Mol Biol Transl Sci 124 (2014) 93-122.

[49] B. Grunow, L. Mohamet, H.A. Shiels, Generating an in vitro 3D cell culture model from zebrafish larvae for heart research, J Exp Biol 218(Pt 8) (2015) 1116-21.

[50] M.S. Yue, J.S. Plavicki, X.Y. Li, R.E. Peterson, W. Heideman, A co-culture assay of embryonic zebrafish hearts to assess migration of epicardial cells in vitro, BMC developmental biology 15 (2015) 50.

[51] I.W.T. Selderslaghs, A.R. Van Rompay, W. De Coen, H.E. Witters, Development of a screening assay to identify teratogenic and embryotoxic chemicals using the zebrafish embryo, Reproductive Toxicology 28(3) (2009) 308-320.

[52] C.A. Ciarlo, L.I. Zon, Chapter 1 - Embryonic cell culture in zebrafish, in: M.W. H. William Detrich, I.Z. Leonard (Eds.), Methods in Cell Biology, Academic Press2016, pp. 1-10.

[53] C.B. Kimmel, W.W. Ballard, S.R. Kimmel, B. Ullmann, T.F. Schilling, Stages of embryonic development of the zebrafish, Dev Dyn 203(3) (1995) 253-310.

[54] S. Choorapoikayil, J. Overvoorde, J. den Hertog, Deriving cell lines from zebrafish embryos and tumors, Zebrafish 10(3) (2013) 316-25.

[55] J. Simmich, E. Staykov, E. Scott, Zebrafish as an appealing model for optogenetic studies, Prog Brain Res 196 (2012) 145-62.

[56] R. Li, T. Beebe, N. Jen, F. Yu, W. Takabe, M. Harrison, H. Cao, J. Lee, H. Yang, P. Han, K. Wang, H. Shimizu, J. Chen, C.L. Lien, N.C. Chi, T.K. Hsiai, Shear stress-activated Wntangiopoietin-2 signaling recapitulates vascular repair in zebrafish embryos, Arterioscler Thromb Vasc Biol 34(10) (2014) 2268-75.

[57] M.R. Harrison, J. Bussmann, Y. Huang, L. Zhao, A. Osorio, C.G. Burns, C.E. Burns, H.M. Sucov, A.F. Siekmann, C.L. Lien, Chemokine-guided angiogenesis directs coronary vasculature formation in zebrafish, Dev Cell 33(4) (2015) 442-54. 
[58] T. Tal, C. Kilty, A. Smith, C. LaLone, B. Kennedy, A. Tennant, C.W. McCollum, M. Bondesson, T. Knudsen, S. Padilla, N. Kleinstreuer, Screening for angiogenic inhibitors in zebrafish to evaluate a predictive model for developmental vascular toxicity, Reproductive Toxicology http://dx.doi.org/10.1016/i.reprotox.2016.12.004.

[59] H.G. Huang, A. Lindgren, X.R. Wu, N.A. Liu, S.O. Lin, High-Throughput Screening for Bioactive Molecules Using Primary Cell Culture of Transgenic Zebrafish Embryos, Cell Rep 2(3) (2012) 695-704.

[60] Experiments on Animal Act, The State Secretary of Health and Environmental Protection, Soestdijk, 2014.

[61] Directive 2010/63/EU of the European parliament and of the council of 22 September 2010 on the protection of animals used for scientific purposes Text with EEA relevance, The European Parliament and the council of the European Union, Official Journal of the European Union, 2010.

[62] M. Westerfield, The Zebrafish Book: A Guide for the Laboratory Use of Zebrafish (Danio Rerio), 4 ed., University of Oregon Press, Eugene2000.

[63] L.N. Pham, M. Kanther, I. Semova, J.F. Rawls, Methods for generating and colonizing gnotobiotic zebrafish, Nat Protoc 3(12) (2008) 1862-75.

[64] K. Henn, Limits of fish embryo toxicity test with Danio rerio as an alternative to the acute fish toxicity test, Center of Organismal Studies Heidelberg (COS), Ruperto-Carola University, Heidelberg, Germany, 2011, p. 91.

[65] L. Fan, P. Collodi, Zebrafish embryonic stem cells, Methods in enzymology 418 (2006) 64-77.

[66] C.A. Schneider, W.S. Rasband, K.W. Eliceiri, NIH Image to ImageJ: 25 years of image analysis, Nat Methods 9(7) (2012) 671-5.

[67] J.A. Thomson, J. Itskovitz-Eldor, S.S. Shapiro, M.A. Waknitz, J.J. Swiergiel, V.S. Marshall, J.M. Jones, Embryonic stem cell lines derived from human blastocysts, Science 282(5391) (1998) 1145-7.

[68] R.H. Adams, K. Alitalo, Molecular regulation of angiogenesis and lymphangiogenesis, Nature reviews. Molecular cell biology 8(6) (2007) 464-78.

[69] J.L. Myhre, D.B. Pilgrim, Cellular differentiation in primary cell cultures from single zebrafish embryos as a model for the study of myogenesis, Zebrafish 7(3) (2010) 255-66. [70] L. Jakobsson, C.A. Franco, K. Bentley, R.T. Collins, B. Ponsioen, I.M. Aspalter, I. Rosewell, M. Busse, G. Thurston, A. Medvinsky, S. Schulte-Merker, H. Gerhardt, Endothelial cells dynamically compete for the tip cell position during angiogenic sprouting, Nat Cell Biol 12(10) (2010) 943-53.

[71] M. Ibrahim, M.K. Richardson, The growth of endothelial-like cells in zebrafish embryoid body culture, Experimental cell research (2017) in press.

[72] A. Gu, W. Tsark, K.V. Holmes, J.E. Shively, Role of Ceacam1 in VEGF induced vasculogenesis of murine embryonic stem cell-derived embryoid bodies in 3D culture, Experimental cell research 315(10) (2009) 1668-82.

[73] M.R. Zanotelli, H. Ardalani, J. Zhang, Z. Hou, E.H. Nguyen, S. Swanson, B.K. Nguyen, J. Bolin, A. Elwell, L.L. Bischel, A.W. Xie, R. Stewart, D.J. Beebe, J.A. Thomson, M.P. Schwartz, W.L. Murphy, Stable engineered vascular networks from human induced pluripotent stem cell-derived endothelial cells cultured in synthetic hydrogels, Acta Biomater 35 (2016) 32-41. [74] Y. Shin, K. Yang, S. Han, H.J. Park, Y. Seok Heo, S.W. Cho, S. Chung, Reconstituting vascular microenvironment of neural stem cell niche in three-dimensional extracellular matrix, Adv Healthc Mater 3(9) (2014) 1457-64. 
[75] Y.H. Hsu, M.L. Moya, P. Abiri, C.C. Hughes, S.C. George, A.P. Lee, Full range physiological mass transport control in 3D tissue cultures, Lab Chip 13(1) (2013) 81-9.

[76] Y.K. Park, T.Y. Tu, S.H. Lim, I.J.M. Clement, S.Y. Yang, R.D. Kamm, In Vitro Microvessel Growth and Remodeling within a Three-Dimensional Microfluidic Environment, Cellular and Molecular Bioengineering 7(1) (2014) 15-25.

[77] M. Tehranirokh, A.Z. Kouzani, P.S. Francis, J.R. Kanwar, Microfluidic devices for cell cultivation and proliferation, Biomicrofluidics 7(5) (2013) 51502.

[78] A.L. Sieminski, R.P. Hebbel, K.J. Gooch, The relative magnitudes of endothelial force generation and matrix stiffness modulate capillary morphogenesis in vitro, Experimental cell research 297(2) (2004) 574-84.

[79] G. Gopinathan, C. Milagre, O.M. Pearce, L.E. Reynolds, K. Hodivala-Dilke, D.A. Leinster, H. Zhong, R.E. Hollingsworth, R. Thompson, J.R. Whiteford, F. Balkwill, Interleukin-6 Stimulates Defective Angiogenesis, Cancer Res 75(15) (2015) 3098-107.

[80] S.L. Park, S.Y. Won, J.H. Song, S.Y. Lee, W.J. Kim, S.K. Moon, Esculetin Inhibits VEGFInduced Angiogenesis Both In Vitro and In Vivo, Am J Chin Med 44(1) (2016) 61-76.

[81] M. Baker, S.D. Robinson, T. Lechertier, P.R. Barber, B. Tavora, G. D'Amico, D.T. Jones, B. Vojnovic, K. Hodivala-Dilke, Use of the mouse aortic ring assay to study angiogenesis, Nature Protocols 7(1) (2012) 89-104. 